\title{
Tailoring gelation mechanisms for advanced hydrogel applications
}

Valeria Nele, Jonathan P. Wojciechowski, James P. K. Armstrong* \& Molly M. Stevens*

Dr. V. Nele, Dr. J. P. Wojciechowski, Dr. J. P. K. Armstrong, Prof. M. M. Stevens

Department of Materials, Department of Bioengineering and Institute of Biomedical Engineering, Imperial College London, Prince Consort Road, London, SW7 2AZ, United Kingdom

* Corresponding author email addresses:

james.armstrong@imperial.ac.uk,m.stevens@imperial.ac.uk

Keywords: hydrogel, trigger, stimuli, polymer, networks.

\begin{abstract}
Hydrogels are one of the most commonly explored classes of biomaterials. Their chemical and structural versatility has enabled their use across a wide range of applications, including tissue engineering, drug delivery, and cell culture. Hydrogels form upon a sol-gel transition, which can be elicited by different triggers designed to enable precise control over hydrogelation kinetics and hydrogel structure. The chosen hydrogelation trigger and chemistry can have a profound effect upon the success of the targeted application. In this Progress Report, a critical overview of recent advances in hydrogel design is presented, with a focus on the available strategies used to trigger the formation of hydrogel networks (e.g., temperature, light, ultrasound). These triggers are presented within a new classification system, and their suitability for six key hydrogel-based applications is assessed. This Progress Report is intended to guide trigger selection for new hydrogel applications and inspire the rational design of new hydrogelation trigger mechanisms.
\end{abstract}




\section{Introduction to Hydrogels}

Hydrogels are defined as "gels in which the swelling agent is water", whereby gels are "nonfluid colloidal networks or polymer networks that are expanded throughout their whole volume by a fluid". ${ }^{[1]}$ Polymer networks can be formed from naturally-derived materials, such as collagen, fibrin, agarose, or alginate. This approach generally offers favorable biocompatibility and biodegradability but can also present issues with immunogenicity, batch-to-batch variation, and poor mechanical properties. Some of these limitations can be addressed by using fully synthetic polymers, such as those based on poly(ethylene glycol) (PEG), poly(acrylamide) (PAM), or poly(vinyl alcohol) (PVA). In particular, synthetic polymers offer greater design flexibility, ease of functionalization, and improved mechanical properties, however, they lack the innate biomolecular cues and biodegradable moieties present in natural biopolymers. ${ }^{[2]}$ Recently, a raft of semi-synthetic materials, such as methacryloyl gelatin (GelMA) and hyaluronic acid methacrylate (HAMA), have been developed with a view to combining the strengths of natural and synthetic polymers. ${ }^{[3]}$ Small molecules, such as surfactants, amphiphiles, peptides, nucleobases, and monosaccharides have also been used to form hydrogels, with crosslinking based on physical interactions or entanglements. In water, the self-assembly of these molecules is driven by intermolecular noncovalent interactions, namely the hydrophobic effect, van der Waals interactions, $\pi-\pi$ interactions, hydrogen bonding, and electrostatic interactions.

Hydrogels were first proposed for biomedical use in the 1960s by Wichterle and Lim, who exploited the hydrophilicity, porosity, and biocompatibility of glycolmethacrylate-based hydrogels to generate soft biomaterial contact lenses. ${ }^{[4]}$ Further studies led to the development of poly(2-hydroxyethyl methacrylate) (pHEMA) hydrogels, which are still commonly used in contact lens manufacturing. Hydrogels are now a ubiquitous presence in biomedical research, with broad applications in drug delivery, cell culture, tissue engineering, and regenerative medicine. ${ }^{[5,6]}$ The diverse requirements of these applications necessitate a careful choice of 
hydrogel system. For example, hydrogels can be designed to encapsulate and controllably release cargo (e.g., cells, nanoparticles, drugs), or undergo stimulated degradation in response to enzymes, ${ }^{[7]}$ hydrolytic conditions,${ }^{[8]}$ light exposure, ${ }^{[9]}$ or changes in $\mathrm{pH} .{ }^{[10]}$

In this Progress Report, we have outlined a selection of available methods for triggering the formation of hydrogels and illustrated these concepts with a critical selection of key studies. We describe mechanism, advantages, and limitations, and present a new classification system for gelation triggers, based on whether they initiate gelation directly (intrinsic gelation) or via the release of gelation triggers from an intermediary component (indirect gelation). We then critically assess the suitability of these triggers for basic and clinical biomedical applications, including in vivo gelation, 3D bioprinting, and hydrogel patterning. Our intention is that this Progress Report will aid the selection of triggers for new hydrogel applications, and inspire the rational design of new gelation trigger mechanisms.

\section{Examples of Different Hydrogel Networks}

Before discussing specific gelation triggers and applications, it is important to first consider the basic chemistry of common hydrogels. In this section, we focus on the different covalent and noncovalent bonding interactions that are used in hydrogelation. We also discuss more complex interactions, including double network hydrogels, polyrotaxane hydrogels, and polymernanoparticle hydrogels. An overview of some of these interactions used for hydrogelation is shown in Table 1.

\subsection{Covalent Bonding}

Hydrogels can be composed of a network of covalently crosslinked polymer chains. The covalent bonds between the polymers create a network structure which, at sufficient crosslinking density, encapsulates water through surface tension. For example, covalently crosslinked gelatin hydrogels can be generated through the formation of amide bonds, typically by 1-ethyl-3-(3-dimethylaminopropyl)carbodiimide (EDC) coupling. In this case, amide bonds 
are formed between primary amine and carboxylic acid sidechain groups of adjacent gelatin chains. ${ }^{[11]}$ Alternatively, multi-arm polymer chains can be covalently crosslinked by polymers or peptides.

For biomedical applications, the most common bonds are those formed from "click chemistry" reactions, since these allow rapid crosslinking under ambient conditions. ${ }^{[12]}$ Examples include copper-catalyzed $^{[13]}$ or strain-promoted ${ }^{[14]}$ azide-alkyne cycloadditions, Michael addition of Michael donors and acceptors, ${ }^{[15]}$ thiol-ene reactions, ${ }^{[16]}$ Diels-Alder [4+2] cycloaddition reactions, ${ }^{[17]}$ disulfide bond formation, ${ }^{[18]}$ and hydrazone or oxime bond formation.${ }^{[19]}$ Covalent crosslinking has also been investigated as a route to form polymer-nanoparticle hydrogels. For example, viscoelastic hydrogels have been formed via a Michael-type addition between thiolfunctionalized PEG chains and liposomes bearing maleimide ${ }^{[20]}$ or acryloyl groups. ${ }^{[21]}$ Cobalt iron oxide magnetic nanoparticles coated with a siloxane-based layer carrying methacrylic moieties have also been used as covalent crosslinkers for the formation of acrylamide-based, magneto-responsive hydrogels. ${ }^{[22]}$ In another example, the surface of cobalt iron oxide nanoparticles was functionalized with aminopropyl silane to form cellulose-based hydrogels covalently crosslinked via EDC coupling. ${ }^{[23]}$

\subsection{Electrostatic Interactions}

Hydrogels networks can also be stabilized by electrostatic interactions. For example, metalalginate hydrogels are composed of divalent cations (e.g., $\mathrm{Ca}^{2+}, \mathrm{Mg}^{2+}, \mathrm{Ba}^{2+}$ ) chelated to carboxylates on adjacent biopolymer strands, a polymer network that is often described using an egg-box model. ${ }^{[24]}$ Alternatively, trivalent cations $\left(e . g, \mathrm{Al}^{3+}, \mathrm{Fe}^{3+}\right)$ can interact with three carboxylate groups to form a more compact network, generating metal-alginate hydrogels with improved mechanical properties. ${ }^{[25]}$ Other biopolymers capable of forming ionicallycrosslinked hydrogels include chitosan, ${ }^{[26]}$ pectin, ${ }^{[27]}$ cellulose, ${ }^{[28]}$ and sodium polygalacturonate. ${ }^{[29]}$ 
Hydrogels can also be generated via coacervation, the liquid-liquid phase separation of oppositely charged polymers in an aqueous medium, a process that is predominantly driven by electrostatic interactions. ${ }^{[30]}$ For example, Hunt et al. reported a triblock copolymer, poly(allyl glycidyl ether-block-ethylene glycol-block-allyl glycidyl ether), which could be post-modified with ionic groups. ${ }^{[31]}$ The resulting poly(anionic) and poly(cationic) polymers formed coacervates upon mixing to yield a hydrogel network. Coacervation can also be used to form temperature-responsive hydrogels by using block copolymers that contain a poly- $[N$ isopropylacrylamide] (PNIPAM) block, such as those derived from PNIPAM- $b$ poly[dimethylaminoethyl methacrylate] and PNIPAM- $b$-poly[acrylic acid]- $b$-PNIPAM. ${ }^{[32]}$ It should be noted that, for all of the cases described in this section, electrostatic interactions do not act in isolation. Rather these bonds are complemented by other noncovalent interactions (e.g., van der Waals interactions, hydrogen bonding) that further stabilize the hydrogel network.

\subsection{Other Noncovalent Interactions}

Hydrogels can also be formed using block copolyelectrolytes, in which ionic blocks impart aqueous solubility and hydrophobic blocks drive network formation through the hydrophobic effect. For example, Nowak et al. reported the gelation of block copolypeptides derived from a poly ionic amino acid block (L-glutamate or L-lysine) and a poly branched chain amino acid block (L-leucine or L-valine). ${ }^{[33]}$ When the length of the hydrophobic block was sufficiently large, $\alpha$-helices or $\beta$-sheets were formed for poly(L-leucine) and poly(L-valine), respectively. These secondary structures were shown to be crucial in forming crosslinked hydrogel networks, with the concentrations needed for gelation increasing as the secondary structure was lost by decreasing the length of the hydrophobic domains. This dependence on secondary structures to form hydrogels at low concentrations (i.e. $<1.0 \mathrm{wt} \%$ ) highlights the importance of complementary noncovalent interactions in stabilizing noncovalent hydrogel networks. 
Noncovalent hydrogels can also be formed from amphiphiles, exploiting interactions such as the hydrophobic effect, hydrogen bonding, $\pi-\pi$ interactions, and van der Waals interactions. ${ }^{[34]}$ These systems typically require a delicate balance between hydrophobicity and hydrophilicity to generate hydrogels. If the amphiphile is too hydrophobic, then it cannot be dissolved in water, and if it is too hydrophilic, there is no driving force to promote self-assembly. Under intermediate conditions, these amphiphiles will typically assemble into anisotropic structures before forming a network structure via noncovalent crosslinks or entanglement. ${ }^{[35]}$ The interactions between molecules are driven by the hydrophobic effect, hydrogen bonding, $\pi-\pi$ interactions, and van der Waals interactions. ${ }^{[34]}$ A well-studied example are the peptide amphiphiles developed by Stupp and co-workers. These amphiphiles consist of a hydrophobic alkyl chain at their $\mathrm{N}$-terminus, a $\beta$-sheet promoting peptide segment, and a charged segment at the C-terminus that can also contain bioactive epitopes. These amphiphiles assemble into cylindrical worm-like micelle structures in water, with the alkyl chain directed towards the core of the structure and the charged segments at the surface. The self-assembly of these amphiphiles is largely driven by the hydrophobic effect but is also stabilized by hydrogen bonding, electrostatic interactions, and van der Waals interactions. In addition to contributing to the overall amphiphilicity of the molecule, the charged segment also allows for electrostatic interactions and network entanglement of the structure fibers upon addition of divalent cations such as $\mathrm{Ca}^{2+} \cdot[36]$

\subsection{Complex Network Interactions}

Hybrid systems consisting of two or more interpenetrating polymer networks can provide physical and mechanical properties that are intermediate between the constituent hydrogels. ${ }^{[37]}$ 
In certain cases, enhanced mechanical properties can be attained by combining short-chain polyelectrolytes and long-chain covalent networks to form double-network hydrogels. Under tensile loads, the dissociation of bonds in the short-chain network dissipates energy while the long-chain network extends to withstand the deformation strain. ${ }^{[38]}$ Accordingly, doublenetwork hydrogels can be designed with an extremely high elastic modulus ( $10 \mathrm{MPa}$ ), failure compressive stress $(\sim 60 \mathrm{MPa})$, and tearing fracture energy $\left(4000 \mathrm{~J} \mathrm{~m}^{-2}\right) \cdot{ }^{[38]}$ Greater recovery from applied deformation can be attained by using short-chain networks with noncovalent crosslinking. For example, Sun et al. combined noncovalent calcium alginate with covalentlycrosslinked PAM, and used additional covalent bonding between the two networks to produce a composite material with unprecedented toughness, stretchability, and stiffness recoverability. ${ }^{[39]}$ Another complex polymer interaction was recently described by Tong et al., who generated polyrotaxane-based hydrogels by threading PEG polymer chains through cyclodextrin rings. The cyclodextrin rings provided high molecular mobility of cell-adhesive ligands and crosslinking points, which enhanced hydrogel remodeling by encapsulated mesenchymal stem cells. ${ }^{[40]}$

\section{Intrinsic Hydrogelation Triggers}

Intrinsic triggers (Figure 1A, Table 2) are defined here as events that initiate hydrogelation by directly altering the physicochemical properties of the base material, or by directly accelerating crosslinking processes. These triggers do not require the use of any intermediary species and can be used to trigger the gelation of both noncovalent and covalent hydrogels.

\subsection{Temperature Changes}

Thermal triggers are ideally suited for many basic science and clinical applications (for more details, please refer to Section 5.). Sol-gel transitions are particularly useful when they occur 
within the range of temperatures commonly used in biomedical science $\left(\sim 4-41{ }^{\circ} \mathrm{C}\right)$. In this temperature range, thermal triggers are most commonly used to initiate the formation of noncovalent interactions which lead to gelation. For example, cooling gelatin below its coil-tohelix transition temperature leads to the formation of a hydrogel network stabilized by triple helix assembly. Solutions of gelatin at a concentration of 5-10 $\mathrm{mg} \mathrm{mL}^{-1}$ undergo a sol-to-gel transition when the temperature is around $30{ }^{\circ} \mathrm{C} \cdot{ }^{[41]}$ Agarose also undergoes gelation upon cooling, with a sol-gel transition temperature that depends upon its exact chemical structure and concentration. ${ }^{[42]}$

Synthetic approaches afford a much higher level of control over the thermogelation process $(e . g$. gelation temperature and rate). This includes many low-molecular-weight gelators that are soluble at high temperatures but self-assemble into hydrated fibrous networks upon cooling. ${ }^{[43]}$ Synthetic materials can also be designed to gel when the temperature is raised, rather than lowered. Lower critical solution temperature (LCST) block copolymers incorporating thermoresponsive hydrophobic segments (e.g., $N$-isopropylacrylamide) within a hydrophilic backbone can undergo hydrogelation upon heating. ${ }^{[4]}$ This occurs due to the low entropy of mixing in these polymer solutions, which is compensated enthalpically through polymer-water interactions (i.e. hydrogen bonding). As the temperature is increased, hydrogen bonding is decreased until it can no longer compensate for the entropic loss of the hydrophobic segments. ${ }^{[44,45]}$ At this point, the hydrophobic effect becomes dominant, which initiates noncovalent collapse of the system and hydrogelation through entanglement of polymer chains. ${ }^{[46]}$ Polymers incorporating PNIPAM, synthetic polypeptides, or poly(caprolactone) are typically used alongside PEG segments that increase the hydrophilicity of the amphiphile. ${ }^{[47]}$ Indeed, the sol-gel transition behaviour of PEG-based di-, ${ }^{[48]}$ tri- $^{[49]}$ and tetra-block ${ }^{[50]}$ copolymers is reasonably well understood and can be synthetically tuned by adjusting molecular weight, ${ }^{[51]}$ segment ratio and length, ${ }^{[50]}$ and chain branching. ${ }^{[52]}$ 


\subsection{Component Mixing}

While temperature changes can be used to directly influence the bond structure of a single biopolymer, other gelation mechanisms require the mixing of two or more liquid components. An example of this approach is the use of attractive interactions that occur between complementary polymer chains. For example, Parisi-Amon et al. used a peptide-based molecular recognition strategy to form a mixing-induced two-component hydrogel (MITCH). Complementary peptide sequences were incorporated in the backbone of two recombinant protein polymers to enable the formation of noncovalent crosslinks upon mixing. ${ }^{[53]}$ This general approach enables highly specific crosslinking events, however, it requires the careful design and synthesis of two complementary recombinant protein polymer systems. A much broader approach is to add crosslinking components that can form hydrogel networks using a single polymer. A common example is the use of zero-length crosslinkers (e.g., EDC) that can generate covalent bonds between polymer chains without being integrated into the hydrogel network. EDC reacts with carboxylic acid groups present on the polymer chains to form $o$ acylisourea. The active ester intermediate can then be attacked by primary amines on adjacent polymer chains, releasing urea as a by-product and yielding a hydrogel network stabilized by covalent amide crosslinks. ${ }^{[54]}$ The common availability of suitable functional groups on most proteins (i.e. aspartic acid, glutamic acid, lysine, hydroxylysine) has led to this approach being widely used to crosslink gelatin, ${ }^{[11,55]}$ collagen, ${ }^{[54]}$ and fibrinogen hydrogels. ${ }^{[56]}$

Hydrogels can also be formed using crosslinkers that can integrate into the network structure. A common example of this is glutaraldehyde, which forms hydrogels via intermolecular crosslinking between amine groups. ${ }^{[57]}$ Alternatively, a range of "click" reactions have also been investigated for hydrogelation (Figure 2). For example, DeForest et al. reported the use of a bis-fluorinated cyclooctyne di-functionalized polypeptide to crosslink a 4-arm PEG tetraazide macromer and form covalent hydrogels within one hour of mixing the two components. 
This crosslinking employed a strain-promoted [3+2] azide-alkyne cycloaddition, which enabled gelation to be performed at $37{ }^{\circ} \mathrm{C}$ and without the use of cytotoxic catalysts $(e . g$., copper $) .{ }^{[58]}$ The Diels-Alder [4+2] cycloaddition reaction between electron-rich dienes (e.g. furan and its derivatives) and electron-poor dienophiles (e.g. maleimides) has also been investigated for hydrogelation. ${ }^{[59]}$ For example, Smith et al. reported the gelation of furan-terminated hyaluronic acid (HA) upon mixing with bis-maleimide PEG at physiological $\mathrm{pH},{ }^{[60]}$ while Madl et al. used a fulvene-functionalized 8-arm PEG crosslinked with an 8-arm maleimide-functionalized PEG. ${ }^{[61]}$ The inverse-electron demand Diels-Alder (IEDDA) reaction between electron-poor 1,2,4,5-tetrazines and electron-rich dienophiles (e.g. norbornene) is an alternative approach for hydrogel crosslinking. ${ }^{[2]}$ As an example, Alge et al. reported that tetrazine-functionalized PEG gelled within minutes of being mixed with a norbornene-functionalized peptidic crosslinker. ${ }^{[62]}$ This crosslinking strategy has also been proposed for the formation of gelatin, ${ }^{[63]}$ alginate, ${ }^{[64]}$ HA, ${ }^{[65]}$ and HA-PEG hydrogels. ${ }^{[66]}$ A less commonly explored reaction is the Huisgen 1,3cycloaddition between hydroximoyl chloride and norbornene, which has been shown to induce the formation of hydrogels within minutes of mixing 4-arm PEG macromers separately functionalized with hydroximoyl chloride or norbornene via the in situ generation of nitrile oxide at physiological $\mathrm{pH} .{ }^{[67]}$ Another common reaction used for hydrogel crosslinking is the thiol-ene Michael addition reaction. ${ }^{[68]}$ For example, PEG-based macromers conjugated with acrylate, diacrylate, maleimide, or vinylsulfone can all be crosslinked via Michael-type addition reactions using dithiol crosslinkers. ${ }^{[69]}$ 4-arm, thiol-terminated PEG macromers have also been shown to form hydrogels within minutes following mixing at physiological conditions with oxanorbornadiene dicarboxylate linkers (Michael acceptors) ${ }^{[70]}$ or with 4 -arm, halidefunctionalized PEG. ${ }^{[71]}$ Other "click" reaction mechanisms which have been explored for hydrogelation include disulfide bond formation ${ }^{[18]}$ and hydrazone or oxime bond formation. ${ }^{[19]}$ 
Noncovalent interactions can also be used for hydrogel crosslinking. For example, the addition of ions can be used to form electrostatic interactions between polymer chains (e.g., calciumalginate hydrogels). A higher degree of control can be exerted by using customized DNA linkers to form annealed crosslinks with $N$-(2-hydroxypropyl)methacrylamide functionalized with complementary polypeptide nucleic acid (PNA) sequences ${ }^{[72]}$ or with DNAfunctionalized polypeptides, ${ }^{[73]}$ while stereocomplex interactions have also been used to form hydrogels via interacting enantiomeric chains. ${ }^{[74]}$ Noncovalent host-guest interactions have also been exploited for hydrogel fabrication, in which a cavitand host and a guest moiety are used to crosslink polymer chains. ${ }^{[75]}$ Using this approach, supramolecular hydrogels have been generated from cyclodextrin cavitands and various guest molecules, ${ }^{[76]}$ or cucurbit $[n]$ uril cavitands complexed with polymers functionalized with methyl viologen or naphthoxy derivatives. ${ }^{[77]}$

Hydrogelation can also be triggered by mixing nanoparticles and polymers. For example, hydrophobic interactions between carboxymethylcellulose-based polymer chains and the surface of polystyrene- or PEG-based nanoparticles can lead to the formation of polymernanoparticle hydrogel networks. ${ }^{[78]}$ Similarly, a combination of hydrophobic and electrostatic interactions were used to form a hydrogel from PEG-based nanoparticles and either carboxymethylcellulose or HA, in the presence of a cationic surfactant. ${ }^{[79]}$ Alternatively, complexation between $\alpha$-cyclodextrins and PEG chains bound to either polymeric nanoparticles ${ }^{[80]}$ or gold-based nanostructures ${ }^{[81]}$ has been used to yield polypseudorotaxane-based hydrogels. Host-guest hydrogel networks have also been formed through the complexation of adamantanefunctionalized polymersomes and HA modified with $\beta$-cyclodextrins. ${ }^{[82]}$ A similar approach can be taken using DNA hybridization, for example, hydrogel networks have been assembled from six-arm DNA strands annealed with complementary DNA sequences bound to various gold nanostructures. ${ }^{[83]}$ More recently, hydrogels have been assembled using coordinate 
covalent bonds formed between carboxylated magnetic iron oxide nanoparticles and catecholfunctionalized polymer chains. ${ }^{[84]}$

\subsection{Change of $\mathrm{pH}$}

A subset of component mixing is the introduction of an acid or base for $\mathrm{pH}$-induced gelation. For example, polymers with functional groups that can be protonated or deprotonated can undergo reversible self-assembly by changing $\mathrm{pH}$. A natural example is collagen, which is typically harvested and stored in a low $\mathrm{pH}$ solution. This acidic environment is used to protonate the basic sidechain residues causing electrostatic charge repulsions that prevent assembly of the triple helices. ${ }^{[85,86]}$ Neutralization of the collagen solution $\mathrm{pH}$ reduces electrostatic repulsion between the helices and leads to hydrogel formation at $37{ }^{\circ} \mathrm{C} \cdot{ }^{[87]}$ A synthetic example are histamine-functionalized poly(allyl glycidyl ether)- $b$-poly(ethylene oxide)- $b$-poly(allyl glycidylether) (PAGE-PEO-PAGE) block copolymers. A micellar solution at $\mathrm{pH} 6.6$, the protonation of histamine above $\mathrm{pH} 7$ leads to the formation of a body-centered cubic lattice hydrogel. ${ }^{[88]}$ Similarly, Fleischer et al. reported a zwitterionic polyethyleneimine that could be used as a pH-responsive hydrogel. Under acidic or basic conditions, charge repulsion of protonated/deprotonated zwitterionic groups were able to maintain the polymer as a liquid. Hydrogelation could be triggered by neutralizing the $\mathrm{pH}$ to enable intermolecular crosslinking through van der Waals interactions, hydrogen bonding, and the hydrophobic effect. ${ }^{[89]}$ Hydrogelation can also be mediated by using covalent reactions that are highly dependent on the solution $\mathrm{pH}$, such as the reaction of hydroxylamine with an aldehyde or ketone to form an oxime bond $(\mathrm{C}=\mathrm{NOH}$ bond $)$. For example, Lin et al. reported the rapid gelation of bis-aldehydefunctionalized PEG and a 4-arm aminooxy crosslinker at $\mathrm{pH}$ 1.5-2.5. Under these conditions, the storage modulus reached a plateau in under $2 \mathrm{~min}$, compared to $10 \mathrm{~h}$ at physiological $\mathrm{pH} .{ }^{[90]}$ This approach has also been used for the catalytic formation of a trishydrazone amphiphile, which forms hydrogels rapidly in acidic $\mathrm{pH} .{ }^{[91]}$ 
The mode of delivery is also important; the direct addition of acid or base can lead to local inhomogeneities in gelation and thus controlled buffer mixing is often preferred. An alternative is the use of gradual $\mathrm{pH}$ changes induced by the addition glucono- $\delta$-lactone, which can be well mixed before slowly releasing protons into solution. This approach has been used for the selfassembly of N-terminal capped dipeptides, producing noncovalent hydrogels with high batchto-batch consistency. ${ }^{[92]}$ Overall, pH-triggered hydrogelation enables the design of hydrogel systems that can respond to the naturally acidic microenvironment of ischemic tissue, such as the infarcted heart. ${ }^{[93]}$

\subsection{Change in Oxidation State}

Another subset of component mixing is the addition of molecules that can induce hydrogelation via a change in oxidation state. Common oxidizing agents include oxygen, periodic acid and its derivatives, and hydrogen peroxide. Enzymes can also induce gelation via changes in oxidation state (for more details, please refer to section 3.5). A common example is the use of catechol groups, which can form reactive semiquinones and quinones in the presence of oxidizing agents. This initiates a polymerization reaction, which makes catechol-functionalized polymers suitable for oxidation-mediated hydrogel crosslinking. ${ }^{[94]}$ Seminal work from Lee et al. showed the gelation of dopamine-functionalized, multi-arm PEG upon the addition of an oxidizing agent, sodium periodate ${ }^{[95]}$ Similarly, the addition of sodium periodate was able to induce the gelation of catechol-terminated poly ( $p$-phenylene oxide)/PEG, ${ }^{[96]}$ gelatin, ${ }^{[97]}$ recombinant fp-1 mussel adhesive protein ${ }^{[98]}$ and HA. ${ }^{[99]}$ Another functional group that enables oxidationmediated crosslinking is pyrogallol. $\mathrm{HA}^{[100]}$ or gelatin ${ }^{[101]}$ have been conjugated with pyrogallol and shown to form hydrogels following the addition of sodium periodate.

\subsection{Enzyme Addition}

Another subset of component mixing is the introduction of enzymes that can catalyze hydrogel crosslinking reactions. ${ }^{[102]}$ For example, transglutaminases are a family of enzymes that 
naturally catalyze the formation of isopeptide bonds between lysine $\varepsilon$-amines and glutamine sidechain amides. This reaction is used to generate intermolecular crosslinks between soluble fibrinogen molecules, a process that is used to generate fibrinogen and fibrin hydrogels. ${ }^{[102]}$ Meanwhile, Su et al. prepared modified heparin/PEGDA hydrogels with crosslinking triggered by the addition of glucose oxidase. Specifically, heparin was functionalized with $N$-hydroxy-5norbornene-2,3-dicarboximide moieties, which were reduced by $\beta$-D-glucose in the presence of glucose oxidase. The resulting radical species were capable of polymerizing PEGDA, to yield self-supporting hydrogels within 30 min at ambient temperature. ${ }^{[103]}$ Lysyl oxidase, a copperdependent enzyme involved in collagen fibrillogenesis, ${ }^{[104]}$ was used by Bakota et al. for the enzymatic crosslinking of a peptide-based hydrogel. Enzymatic reduction of peptidic lysine sidechain residues formed aldehydes, which then underwent interpeptide crosslinking (aldolic condensation or a Schiff base reaction) to produce covalent hydrogels. ${ }^{[105]}$ Another enzyme system that has been used for hydrogelation is the oxidative coupling of tyramine in the presence of hydrogen peroxidase (HRP) and hydrogen peroxide. This catalysis has been used to crosslink tyramine-functionalized $\mathrm{HA}^{[106]}$ and glycopolypeptide copolymers, ${ }^{[107]}$ with the latter used for in vivo hydrogelation. Oxidation-mediated hydrogel crosslinking triggered by HRP in the presence of hydrogen peroxide has also been shown for PEG ${ }^{[108]}$ and gelatin. ${ }^{[109]}$ More recently, Carthew et al. have shown that HRP could be used to trigger the formation of PEG-gelatin hydrogels in the absence of hydrogen peroxide. In this case, HRP oxidized dihydrotetrazine moieties attached to 4-arm PEG macromers, which subsequently reacted with norbornene-functionalized gelatin via the IEDDA reaction. ${ }^{[110]}$

In summary, enzyme-based approaches enable catalyzed crosslinking that can generally occur at physiological $\mathrm{pH}$ and temperature with high substrate specificity and without the need for radical initiators or other chemical additives. ${ }^{[102]}$

\subsection{Electromagnetic radiation}


Electromagnetic radiation is widely-used to trigger hydrogel crosslinking. ${ }^{[111]}$ However, in most cases this approach requires the presence of an intermediate, such as photoinitiators ${ }^{[12]}$ or plasmonic nanoparticles $^{[113,114]}$ (for more details, please refer to Section 4.3.). However, light can also be used to directly trigger gelation. For example, Farahani et al. proposed a strategy in which light is used to uncage reactive groups for hydrogel crosslinking. An 8-arm PEG was functionalized with an alkoxyamine caged by 2-(2-nitrophenyl) propyloxycarbonyl, which undergoes a $\beta$-elimination reaction upon irradiation with UV light $(\lambda=365 \mathrm{~nm})$. This process was used to expose alkoxyamine, which could then react with a benzaldehyde-terminated 8arm PEG via oxime ligation to generate covalently-crosslinked hydrogels. ${ }^{[115]}$

\section{Indirect Hydrogelation Triggers}

The second category of hydrogelation triggers involves indirect mechanisms (Figure 1B, Table 3). For example, using a trigger to stimulate the production of reactive species from initiator molecules or to liberate crosslinking species from carriers. Commonly used carriers are liposomes i.e. vesicles that comprise an aqueous core surrounded by a phospholipidic bilayer. ${ }^{[16]}$ This structure enables the encapsulation of both hydrophobic and hydrophilic compounds, ${ }^{[117]}$ which can be released by stimulated membrane perturbation (transient pore formation, particle disruption, or phase changes). ${ }^{[18]}$ In this section, the use of initiators, liposomes, and other stimuli-responsive systems will be discussed in the context of triggered hydrogelation.

\subsection{Temperature}

Liposomes are particularly suited as thermoresponsive carriers as they exhibit thermotropic phase transitions. These transitions are associated to changes in membrane fluidity and lipid packing, which allow temperature-dependent cargo release. ${ }^{[19]}$ For example, Westhaus et al. loaded calcium ions into a formulation of microscale liposomes (90 mol\% 1,2-bis(palmitoyl)- 
sn-glycero-3-phosphocholine and $10 \mathrm{~mol} \%$ 1,2-bis(myristoyl)-sn-glycero-3-phosphocholine) and then used temperature to release the ionic cargo. Heating from room temperature to $37{ }^{\circ} \mathrm{C}$ triggered the electrostatic complexation of alginate hydrogels in under $30 \mathrm{~s} .{ }^{[120]}$ The versatility of this approach was demonstrated by using the thermally-released ions to activate a calciumdependent transglutaminase, which was then able to catalyze the formation of fibrinogen ${ }^{[120]}$ and PEG-based hydrogels. ${ }^{[121]}$ Liposome formulations can be readily adjusted to exhibit phase transitions at different temperatures, enabling the rationale design for different applications. For example, a system that undergoes gelation at $37^{\circ} \mathrm{C}$ could be used for controlled in vivo gelation at body temperature. Alternatively, a carrier that is stable against leakage at body temperature $\left(37^{\circ} \mathrm{C}\right)$ and releases its cargo at higher temperatures $\left(\sim 41^{\circ} \mathrm{C}\right)$ would enable in vivo gelation by remote heating mechanisms (see Section 4.3.).

\subsection{Ultrasound}

Ultrasound-triggered release of cargo has been widely used for drug delivery ${ }^{[122]}$ and has very recently been applied to initiate hydrogelation. ${ }^{[123]}$ There are a number of ultrasound-responsive carriers, including many liposomes, ${ }^{[124,125]}$ micelles ${ }^{[126]}$ polymersomes, ${ }^{[127]}$ microbubbles, ${ }^{[128,129]}$ and phase-shift nanodroplets. ${ }^{[130]}$ There are also several different mechanisms that can be used for cargo release. These include the use of high-frequency ultrasound to induce mild hyperthermia or cavitation phenomena, ${ }^{[131]}$ and the use of lowfrequency ultrasound to stimulate transient pore formation in liposomal membranes. ${ }^{[132]}$ The latter approach was used by Nele et al. to liberate liposomal calcium ions that could then activate transglutaminase to catalyze the covalent crosslinking of fibrinogen networks. The enzyme kinetics, gelation rate and final hydrogel properties could all be controlled by varying the ultrasound exposure time, moreover, enhanced ion release was demonstrated using 
liposome-microbubble conjugates. Microbubbles are commonly used in combination with high-frequency fields and clinically-used focused ultrasound systems, which offers the opportunity to remotely trigger gelation with high spatiotemporal control ( 1 mm) and at high penetration depths $(\sim 13 \mathrm{~cm}$ focal length for tissue, depending on the parameters used). ${ }^{[123,129,133]}$

\subsection{Electromagnetic Radiation}

Ultraviolet and visible light has been extensively used to trigger gelation by using photoinitiator molecules, ${ }^{[11]}$ which are able to absorb the incident radiation and form species that can mediate a polymerization reaction. ${ }^{[134]}$ Common photoinitiators generate radicals via Norrish type I or II reactions. These include aromatic carbonyl compounds that form radicals by homolytic bond cleavage, aromatic ketones that generate radicals through hydrogen abstraction, and onium salts, such as ammonium persulfate that dissociate in solution to produce radical sulfate anions. ${ }^{[135,136]}$ Vinyl functionalized polymers are commonly used as base materials in hydrogel photocrosslinking, for instance, PEG diacrylate (PEGDA), ${ }^{[137]}$ GelMA, ${ }^{[138]}$ HAMA, ${ }^{[139]}$ methacrylated collagen, ${ }^{[140]}$ methacrylated alginate ${ }^{[141]}$, and methacryloyl glycol chitosan. ${ }^{[142,143]}$ Vinyl polymerization proceeds via free-radical polymerization, in which a free radical attacks a vinyl group, forming a covalent bond with the initiator and transferring the radical to the vinyl group. This radical can react with additional vinyl groups on adjacent polymers to generate covalently crosslinks, however, this is a relatively uncontrolled process that can produce heterogeneous network structures. ${ }^{[144,145]}$ An alternative to free-radical photopolymerization is the use of step-growth mechanisms, such as thiol-norbornene crosslinking. Here, a photoinitiator radical abstracts a thiol proton to form a thiyl radical, which then reacts with norbornene to produce a norbornane radical that can abstract another thiol proton, and so forth. This reaction has been used to produce hydrogels using norbornene- 
functionalized analogs of PEG, ${ }^{[145,146]}$ gelatin, ${ }^{[147]}$ or $\mathrm{HA}^{[148]}$ crosslinked with dithiothreitol or dithiolated peptides.

The use of light as a trigger for hydrogel formation is particularly attractive as it offers high spatiotemporal and remote control. However, one limitation is that high-frequency radiation (UV, short-wavelength visible light) has a limited penetration depth through opaque matter (e.g., tissue). This has led to strategies employing red light or near-infrared (NIR) light, which offer reduced scattering compared to higher frequency radiation. ${ }^{[149]}$ The use of alkyl-cobalaminbased photoinitiators has enabled the formation of acrylamide- or PEG-based hydrogels within 5 min following red light irradiation. ${ }^{[150]}$ In another example, red light was used to trigger the oxidation of dihydrotetrazine conjugated to 4-arm PEG, which reacted with a norbornenefunctionalized 4-arm PEG via the IEDDA reaction to form self-supporting hydrogels. ${ }^{[151]}$ Meanwhile, NIR light $(\lambda=980 \mathrm{~nm})$ has been used to irradiate upconversion nanoparticles coated with a Pluronic ${ }^{\circledR}$ F127 diacrylate, which led to the emission of green light that could photocrosslink the Pluronic diacrylate and a PEG acrylate component in the presence of a photoinitiator. ${ }^{[152]}$ While this approach demonstrates feasibility, the use of upconversion nanoparticles for hydrogelation is a relatively new field and more work is needed to expand the library of available, biocompatible reaction mechanisms.

An alternative approach is to use NIR to initiate heating of plasmonic nanostructures, which can then be used to trigger thermally-induced gelation. Gramlich et al. showed that NIR light $(\lambda=808 \mathrm{~nm})$ could be used in combination with gold nanorods and a thermal initiator to trigger the crosslinking of HAMA. ${ }^{[13]}$ Using a similar approach, transdermal gelation of PEGDA was achieved following the use of NIR irradiation $(\lambda=785 \mathrm{~nm})$ to trigger local hyperthermia (37 $42{ }^{\circ} \mathrm{C}$ ) and activate a thermal initiator at the injection site. ${ }^{[14]}$ NIR-induced heating has also been used to trigger the release of reactive cargo from thermo-responsive liposomes containing plasmonic nanostructures in the lumen ${ }^{[153]}$ or on the membrane surface. ${ }^{[154,155]}$ For example, 
microscale liposomes loaded with gold nanorods and calcium ions have been used to induce alginate gelation upon NIR light exposure, an approach that was used for transdermal in vivo gelation. ${ }^{[156]}$ Moreover, this approach enabled spatiotemporal control over hydrogel stiffness by changing the laser intensity or irradiation time, or by structuring the light exposure using photomasks. An alternative, which avoids the use of local heating, is the direct release of cargo from light-responsive liposomes using photo-isomerization, photo-oxidation, or photocleavage. ${ }^{[157]}$ Zhang et al. prepared a formulation of calcium-loaded diplasmenylcholine liposomes containing bacteriochlorophyll $a$, which produced singlet oxygen when excited with NIR radiation $(\lambda=800 \mathrm{~nm})$. The singlet oxygen was able to cleave the diplasmenylcholine in the liposome membrane, which liberated the calcium ions and triggered the formation of fibrinogen hydrogels via activated transglutaminase catalysis. ${ }^{[158]}$

\section{Applications}

Hydrogels possess a range of material properties that are highly suited for applications in tissue engineering, regenerative medicine, cell culture, drug delivery, soft robotics, biosensing, and bioelectronics. ${ }^{[6]}$ Hydrogels can also undergo material changes (e.g., swelling, degradation, fluorescence shifts) in response to specific chemical stimuli, which are used in drug delivery, ${ }^{[159]}$ soft robotics, ${ }^{[160,161]}$ and biosensing platforms. ${ }^{[162,163]}$ This section will detail recent progress in six hydrogel applications that require a careful choice of hydrogel chemistry or gelation trigger.

\subsection{Hydrogels for 3D Cell Culture}

Hydrogels are well-established platforms for various cell culture applications, such as the study of biological processes or the development of cell-based therapies. ${ }^{[164]}$ Cells can be cultured on top of prefabricated hydrogels or encapsulated within hydrogels or microgels. ${ }^{[165]}$ In addition, hydrogel encapsulation is also widely used for the culture of organoids. ${ }^{[166]}$ Compared to glass and plastic substrates, hydrogels can provide cells with a biological, mechanical, and 
topographical environment that more closely replicates physiology. ${ }^{[167]}$ In particular, hydrogel encapsulation can provide a 3D environment that mimics the extracellular matrix, thus supporting or modulating certain cell behavior. ${ }^{[168,169]}$ For example, the filamentous structure of the native extracellular matrix can be modeled using peptides, block copolymers, nanoparticles, or nanofibers designed to undergo supramolecular assembly into fibrillar hydrogels. ${ }^{[170]}$ There are two contrasting approaches to replicate the biology of the extracellular matrix: natural hydrogels present an array of cell-instructive cues, alternatively, synthetic hydrogels allow a reductionist approach by incorporating defined quantities and combinations of specific biomolecules into an inert polymer backbone ${ }^{[171]}$ Such strategies have been used to exert control over key cellular processes, such as adhesion, spreading, migration, proliferation, and differentiation. For example, hydrogels able to sequester and subsequently release growth factors have been used to modulate the differentiation of stem cells ${ }^{[172]}$ or cardiac progenitor cells, ${ }^{[173]}$ while the spacing of adhesion moieties within hydrogels has been used to control the spreading of endothelial cells. ${ }^{[174]}$ In another work, PEG hydrogels with varying densities of adhesive peptides were used to study the migration of fibroblasts. ${ }^{[175]}$

Early work by Engler et al. demonstrated that matrix stiffness could be used to direct the differentiation of mesenchymal stem cells, ${ }^{[176]}$ and in recent years, there has been intensive research aimed at understanding the mechanisms underpinning mechanotransduction. In this context, hydrogels represent an ideal platform, due to their tunable mechanical properties. Some approaches have focused on the production of hydrogels with various stiffnesses, ${ }^{[168,177]}$ while other approaches have used hydrogels with mechanical properties that can be dynamically tuned over time. ${ }^{[178-180]}$ Mechanical changes can occur through structural alterations in the hydrogel network instigated by enzymatic reactions. For example, Khetan et al. produced HAMA hydrogels crosslinked with peptide sequences that could be cleaved by matrix metalloproteinases secreted by encapsulated stem cells. This degradable hydrogel enabled 
increased cell traction and promoted osteogenesis, in contrast to equivalent non-degradable hydrogels, which favored adipogenesis. ${ }^{[181]}$ A more complex system was demonstrated by Parmar et al., who crosslinked collagen-mimetic hydrogels with two different peptide sequences, one responsive to matrix metalloproteinase and the other to aggrecanase. ${ }^{[182]}$ This system, applied to cartilage tissue engineering, enabled a sequential degradation profile that was tuned to the chondrogenesis of mesenchymal stem cells. Other examples have used cellmediated hydrogel degradation to study the behavior of neural progenitor cells, ${ }^{[183]}$ to promote the formation of vascular-like structures by endothelial cells, ${ }^{[184]}$ and to engineer cartilaginous tissue constructs. ${ }^{[146]}$

\subsection{In Vivo Gelation}

Many tissue engineering, regenerative medicine, and drug delivery approaches seek to implant or inject preformed materials into the body. A counter-strategy is the use of in vivo gelation, which offers a minimally-invasive approach to material delivery. One approach is to initiate a gelation process immediately prior to administration, for example, by mixing components during injection from a single- or double-barrel syringe. Eckhouse et al. reported a rapid in vivo gelation process $(<1 \mathrm{~min})$ following intramyocardial administration of hydroxyethyl methacrylate functionalized HA and redox initiators. This approach was used for the sustained release of tissue inhibitor of matrix metalloproteinases-3 (TIMP-3), which prevented adverse remodeling in a porcine model of myocardial infarction. ${ }^{[185]}$ A more recent report showed that the mixing of maleimide-functionalized PEG macromers and thiol-terminated peptide crosslinkers upon injection generated covalently-crosslinked PEG hydrogels in vivo. This system successfully supported islet vascularization and survival in a murine model of type I diabetes (Figure 3A). ${ }^{[186]}$ Meanwhile, Bu et al. reported in vivo gelation within 6 s of coinjecting amine-terminated 4-arm PEG and 4-arm PEG functionalized with succinimidyl succinate. The resulting hydrogel was used as a degradable sealant for liver hemostasis in a 
rabbit model of liver bleeding, where it effectively prevented adhesion of the surrounding tissue. ${ }^{[187]}$

In all of these cases, the rate of reaction upon mixing is crucial. If the gelation occurs too quickly, the syringe needle can become blocked, conversely, the components can diffuse away from the target site if the reaction proceeds too slowly. Another approach is to trigger the gelation of a liquid precursor solution after administration. In this regard, a natural candidate is the use of body temperature $\left(37^{\circ} \mathrm{C}\right)$ or stimulated hyperthermia $\left(37-43^{\circ} \mathrm{C}\right)$ to thermally trigger in vivo gelation. ${ }^{[156]}$ For example, extracellular matrix hydrogels undergo gelation at body temperature and have been investigated as injectable formulations for the treatment of several diseases. ${ }^{[188]}$ For example, a pilot human clinical trial has recently been conducted to assess the safety of a hydrogel derived from cardiac extracellular matrix (VentriGel) for percutaneous transendocardial injection in cardiac repair. ${ }^{[189]}$ Control over the gelation kinetics remains a challenge, and uneven gelation can occur due to heat transport phenomena across the material. Furthermore, deep-tissue injection of thermo-responsive materials in deep tissue can still result in premature gelation and catheter obstruction. ${ }^{[190]}$

The use of remote triggers, such as light or ultrasound, may be able to overcome some of the drawbacks associated with component mixing and thermal gelation. In this context, the choice of gelation trigger depends on the target location within the body. UV and visible light are constrained by limited tissue penetration, nevertheless, these radiation frequencies have been used to trigger in vivo gelation in optically-transparent tissue (e.g., cornea) or surgicallyexposed sites (e.g., open-knee surgery). A pilot human clinical study tested the use of UV light to trigger the gelation of PEGDA injected into a cartilage defect with photoinitiator and HA as a viscosity modifier. The formation of a covalently-crosslinked PEG hydrogel was shown to improve endogenous tissue repair, when compared to the unexposed control group. ${ }^{[191]}$ More recently, Sani et al. investigated whether photocrosslinkable GelMA hydrogels could be used 
for cornea repair. The hydrogel precursor solution was injected in the cornea stromal defect of a rabbit model and then crosslinked by exposure to visible light $(\lambda=450-550 \mathrm{~nm})$ (Figure 3B). The resulting hydrogel effectively adhered to the corneal defect, remained transparent for up to $14 \mathrm{~d}$, and supported corneal re-endothelialization. ${ }^{[192]}$ Meanwhile, UV light $(\lambda=360-$ $480 \mathrm{~nm}$ ) has been used for the in vivo crosslinking of hydrogel sealants, including GelMA composites $^{[193]}$ and methacryloyl-substituted tropoelastin ${ }^{[194]}$ in various animal models.

An alternative to triggered in vivo gelation is the use of shear-thinning hydrogels, which undergo reversible gel-to-liquid transitions under applied shear stress. In these cases, the material adopts a fluid form during injection and a hydrogel state before and after administration. Rodell et al. generated shear-thinning hydrogels using HA functionalized with either cyclodextrin or adamantane moieties to enable host-guest complexation. These hydrogels were evaluated for the preventive treatment of ventricular dilation after myocardial infarction, ${ }^{[195,196]}$ while similar hydrogels loaded with miRNAs were tested for cardiac regeneration. ${ }^{[197]}$ Shearthinning hydrogels can also be formed by exploiting physical interactions between polymer chains and nanosilicates. For example, Avery et al. developed a composite hydrogel from gelatin and silicate nanoplatelets that could be injected with a catheter for vascular embolization in murine and porcine models (Figure 3C). The authors reported complete recovery of the shear modulus post-injection with the resulting hydrogel successfully used to occlude blood vessels. ${ }^{[198]}$ Similarly, Pang et al. reported the in vivo injection and gelation of a shear-thinning hydrogel formulated from the electrostatic interaction between silicate nanoplatelets and alginate. The hydrogel was endoscopically injected in a porcine model to evaluate its ability to form stable submucosal cushions. ${ }^{[199]}$

\subsection{Hydrogel Patterning}

Patterning of chemical, physical, and structural features within hydrogels offers the opportunity to modulate the cell-material interface in a spatial and/or temporal fashion. One method is to 
structure the polymer or cargo components within a precursor solution before triggering gelation. For example, Li et al. recently used fluid density differences to generate compositional and mechanical gradients captured within various hydrogels (e.g., agarose, gellan gum, GelMA). ${ }^{[172]}$ A gradient of bone morphogenetic protein 2 was formed in GelMA and used to stimulate the local osteogenesis and mineralization of encapsulated human mesenchymal stem cells for osteochondral tissue engineering (Figure 4A). More selective manipulation can be achieved using magnetic fields, for example, Li et al. also showed that superparamagnetic nanoparticles sequestered with bone morphogenetic protein 2 could be magnetically patterned into a gradient in an agarose hydrogel precursor solution. Thermal gelation of the agarose was used to immobilize the gradient for osteochondral tissue engineering. ${ }^{[200]}$ Ultrasound standing waves have also been used for hydrogel patterning, for example, Nichols et al. used acoustic radiation forces to generate geometric arrays of $\mathrm{pH}$-responsive, dipeptide-based coacervate microdroplets (Figure 4B). Glucono- $\delta$-lactone was used to slowly lower the $\mathrm{pH}$ and trigger the formation of dipeptide hydrogels. ${ }^{[201]}$

Alternatively, techniques such as mask-based photolithography, single-photon laser-scanning lithography, and multi-photon laser-scanning lithography have been used for high-resolution, chemical modification of pre-formed hydrogels. ${ }^{[111,134]}$ Examples include the use of thiol-ene chemistry to photopattern arginylglycylaspartic acid (RGD) peptides onto nanofibrous hydrogels to control cellular adhesion, ${ }^{[202]}$ and the use of oxime ligation and $o$-nitrobenzyl ester photoscission for the attachment and release of proteins for reversible stem cell differentiation. ${ }^{[203]}$ Similar approaches have been used to form biomolecular gradients. For example, Mosiewicz et al. used light to uncage a peptide substrate on PEG-based hydrogels in order to enzymatically tether free peptides, ${ }^{[204]}$ while Fisher et al. generated HA-based hydrogels photopatterned with a gradient of epidermal growth factor to study cancer cell invasion in a breast cancer model. ${ }^{[205]}$ Shadish et al. recently proposed an alternative strategy 
that avoided direct conjugation of proteins to the polymer backbone. In this work, recombinant fusion proteins were engineered comprising a photocleavable protein and a target protein. The photocleavable protein was bound to the polymer backbone of a PEG-based hydrogel and light was used to controllably release the target protein. ${ }^{[206]}$ A limitation of most photopatterning methods is that they generally do not allow for repeated patterning events, which restricts their use for more dynamic cell culture studies. However, Grim et al. recently reported a new approach that used light to iteratively pattern and release bioactive molecules within a hydrogel network. In this work, PEG was functionalized with pendant allyl sulfide groups that acted as chain-transfer agents for repeated tethering and release of thiolated peptides and proteins. ${ }^{\text {[207] }}$ Photopatterning can also be used to fabricate hydrogel stiffness gradients. ${ }^{[208]}$ For example, Liu et al. generated fusion proteins comprising a stimuli-responsive protein and its binding protein counterpart, which were used to form crosslinked PEG hydrogels. UV light exposure induced a conformational change in the responsive protein, triggering a binding event that locally increased hydrogel stiffness due to network tightening (Figure 4C). ${ }^{[209]}$ Dual biochemical and stiffness gradients have also been patterned within hydrogels using controlled light exposure,${ }^{[210,211]}$ a method that has been used to study cell behavior in a high-throughput fashion. Moreover, structured light exposure has been exploited for subtractive manufacturing of hydrogels, an approach that has particular relevance in creating perfusable and cellularized channels. For example, photomasks were used to generate customized microchannels $(20 \mu \mathrm{m}$ width) within GelMA hydrogels crosslinked with photodegradable linkers, with post-seeded cardiomyocytes preferentially aligned along the length of the microchannels. ${ }^{[212]}$ Meanwhile, laser photoablation and multiphoton lithography approaches have been employed to generate complex vascularized networks within collagen ${ }^{[213]}$ or PEG-based hydrogels. ${ }^{[213,214]}$ Grigoryan et al. recently introduced the use of food dyes as photo-absorbers for hydrogel photopatterning. This approach was used to pattern highly complex and perfusable vascular networks within 
PEG-based hydrogels, which were used to generate perfusable lung-mimetic hydrogel constructs. ${ }^{[215]}$

\subsection{Hydrogel-based Biofabrication}

One of the main challenges in tissue engineering and regenerative medicine is the fabrication of synthetic constructs that can replicate the biological and structural functionality of natural tissues. This need has fostered the development of a wide range of biofabrication techniques, where the term biofabrication indicates "the automated generation of structurally-organized, biologically-functional products from living cells, bioactive molecules, biomaterials, cell aggregates such as microtissues or hybrid cell-material constructs through bioprinting or bioassembly". ${ }^{216,217]}$

Hydrogels are used as the biomaterial component in many biofabrication strategies, as their phase behavior and trigger mechanisms enable flexible manufacturing methods. A relatively simple hydrogel biofabrication strategy is micromolding, in which a hydrogel precursor solution is deposited into a mold, crosslinked, and then demolded. This approach has been used to fabricate shape-defined hydrogel constructs from enzymatically-crosslinked collagen/fibrinogen, ${ }^{[218]}$ thermo-setting gelatin, ${ }^{[219]}$ and photocrosslinked acrylated PEG, acrylamide, and HAMA. ${ }^{[220,221]}$

Hydrogels have also been used in many different printing modalities, such as droplet bioprinting, ${ }^{[222]}$ stereolithography (SLA), ${ }^{[223,224]}$ and two-photon polymerization. ${ }^{[225]}$ Recently, Nuñez Bernal et al. introduced a volumetric bioprinting approach that involved the projection of light patterns onto a rotating container filled with a cell-laden GelMA precursor solution (Figure 5A). ${ }^{[226]}$ This method offers the benefit of printing large cellularized hydrogel structures in a single step within tens of seconds. Most commonly, extrusion printing is used to fabricate hydrogel structures using materials that undergo sol-gel transitions prior to printing, ${ }^{[227]}$ during extrusion, ${ }^{[228]}$ or after deposition. ${ }^{[229]}$ For example, Ouyang et al. used HA 
functionalized with $\beta$-cyclodextrin and adamantane groups to mediate printing by guest-host assembly. Moreover, the presence of HA-conjugated methacrylate moieties enabled secondary photocrosslinking to provide further stabilization of the printed structure (Figure 5B). ${ }^{[229]}$ Alternative approaches seek to partially crosslink bioinks into soft, extrudable gels that can be further crosslinked post-printing, ${ }^{[227]}$ or to photocrosslink methacrylate-, acrylate-, or norbornene-modified biopolymers immediately prior to deposition. ${ }^{[228]}$

Various additives have been incorporated within hydrogel bioinks in order to provide enhanced printability or bestow additional structural or functional properties. For example, Chen et al. showed that the addition of a rheology modifier (Carbomer) allowed the direct ink writing of various different hydrogels (Figure 5C). ${ }^{[230]}$ Nanoclay particles have also been used to enable printing of stretchable and tough PEG-alginate interpenetrating network hydrogels, ${ }^{[231]}$ while shear-aligned cellulose fibrils have been used to direct shape transitions of printed acrylamide hydrogels upon swelling. ${ }^{[232]}$ Meanwhile, Highley et al. formulated granular, microgel-based bioinks with shear-thinning and self-healing properties that could be used for either unsupported or supported extrusion printing (Figure 5D). ${ }^{[233]}$ Pluronic ${ }^{\circledR}$ F127 has also been used as a bulk additive to template the printing of cell-laden alginate bioinks for cartilage and bone tissue engineering. The Pluronic offered a rapid thermal gelation mechanism for efficient extrusion printing, while the reversible nature of the sol-gel transition enabled its release during the electrostatic crosslinking of the alginate component. ${ }^{[234]}$ This process has also been exploited to create templated microchannels to support nutrient transport in 3D printed structures. ${ }^{[235,236]}$ A similar approach used the reversible thermosetting of gelatin to fabricate an interconnected network of channels throughout GelMA hydrogels. As a cytocompatible material, the gelatin bioink could be pre-loaded with endothelial cells to form uniform vascular networks without needing to post-seed cells into channels. ${ }^{[237]}$

\subsection{Pericellular Gelation}


The functionalization of living cells with material coatings can be used to provide cells with a protective barrier or augmented properties. ${ }^{[238]}$ Applications include the fabrication of bioelectronic devices, the directed assembly of multicellular structures for tissue engineering, and the therapeutic delivery of cells. ${ }^{[239]}$ The deposition of a thin hydrogel layer around cells can be achieved using droplet microfluidics. For example, Kamperman et al. demonstrated the fabrication of monodisperse microgels encapsulating single cells, in which a delayed hydrogel crosslinking reaction was used to prevent off-center cell encapsulation. ${ }^{[240]}$ A different approach is to decorate the cell membrane surface with molecules that can then initiate pericellular gelation. For example, Deller et al. bound complexes of thrombin and a polymer surfactant to the membrane of human mesenchymal stem cells, with the surface-bound enzyme able to catalyze the formation of a thin layer of fibrin hydrogel (Figure 6A). The encapsulated cells were shown to proliferate for several weeks and could undergo both adipogenic and osteogenic differentiation. ${ }^{[241]}$ In other work, Sakai et al. used horseradish peroxidase (HRP) conjugated to a biocompatible anchor molecule (BAM) inserted into the membrane of various cell lines, such as mouse embryonic fibroblasts. In the presence of millimolar concentrations of hydrogen peroxide, the HRP enzyme was able to catalyze the oxidative coupling of phenols to form polyphenolic networks. This approach was used to generate pericellular hydrogel layers using a variety of phenol-modified polymers, including alginate, HA, and PVA. ${ }^{[242]}$

Other nonenzymatic approaches include the use of maleimide-functionalized lipids inserted into the cytoplasmic membrane of rabbit erythrocytes, which could react with thiolated PEG macromers or thiolated alginate. These secondary species could in turn react with maleimidefunctionalized PEG or lipid micelles to form covalent hydrogel coatings. ${ }^{[243]}$ A similar approach was used to form DNA-polyelectrolyte hydrogels on the surface of various mammalian cell lines, including smooth muscle cells, hematopoietic cells, and human mesenchymal stem cells. Cholesterol was used to anchor a single DNA strand into cell membranes, where it was able to 
hybridize free DNA hairpins to create an alginate-DNA polymer network hydrogel that could be further crosslinked using polylysine (Figure 6B). Coated murine mesenchymal stem cells were intravenously injected in mice; $30 \%$ of the injected cells were detected after $7 \mathrm{~d}$, indicating that this approach could be used to shield transplanted cells from the host immune response. ${ }^{[244]}$ An alternative strategy was proposed by Mao et al., who used a microfluidic device to create a water-in-oil emulsion of alginate prepolymer and various cell types, including endothelial cells and marrow stromal cells. These cells were pre-coated with $\mathrm{CaCO}_{3}$ nanoparticles, which dissolved after the introduction of acetic acid to the oil phase. The free calcium ions complexed with the alginate polymer to form a pericellular hydrogel shell (thickness $\sim 6 \mu \mathrm{m}$ ). This method was also used to generate single cell microgels of calcium-alginate with either collagen or fibrin that supported the osteogenesis of entrapped marrow stromal cells. ${ }^{[245]}$ In a follow-up study, calcium-alginate/polylysine microgel encapsulation was used to increase the circulatory halflife of intravenously-administered mesenchymal stem cells in a murine bone marrow transplant model. $^{[246]}$

\subsection{Nanoparticle-templated Nanogel Fabrication}

Nanometer-sized hydrogels (nanogels) have emerged as a versatile drug delivery platform, allowing a relatively high quantity of large biomolecules to be encapsulated and released. ${ }^{[247]}$ Traditional approaches generally involved the crosslinking of amphiphilic polymer nanostructures or the use of inverse emulsion polymerization. ${ }^{[248]}$ Alternatively, nanogel fabrication can be templated by nanoparticles. ${ }^{[249-255]}$ For example, Park et al. fabricated liposome-templated nanogels by rehydrating lyophilized liposomes in a solution of a polylactide-PEG-polylactide (PLA-PEG-PLA) diacrylate copolymer and photoinitiator, and then irradiating the suspension with UV light. This nanogel platform, loaded with a small TGF$\beta$ inhibitor, was tested for the treatment of subcutaneous and metastatic melanoma in a mouse model. ${ }^{[249]}$ Similarly, PAM-based nanogels have been obtained by encapsulating acrylamide 
monomers, $\quad N, N^{\prime}$-methylene-bisacrylamide crosslinker, and photoinitiator within phosphatidylcholine liposomes, and then photocrosslinking following liposome extrusion. In this case, a super-oxide dismutase was encapsulated within the nanogel while the lipid bilayer membrane provided a barrier to control the diffusion of both the enzyme substrate and the reaction products. ${ }^{[250]}$

Liposome-templated nanogels have also been fabricated by using thiol-ene click chemistry to photocrosslink allyl-functionalized polyglycidol with PEG dithiol. Both stepwise and one-pot approaches were tested; in each case, the hydrogel components were introduced into the liposome core with subsequent exposure to UV light $(\lambda=365 \mathrm{~nm})$ yielding liposome-templated nanogels. ${ }^{[251]}$ In another study, the host-guest interaction between polyethyleneimine chains functionalized with cyclodextrin or adamantane was exploited to form nanogels within cationic liposomes (Figure 6C). A ten-fold enhancement in the encapsulation efficiency of Cas9 protein was observed for the liposome-templated nanogels (63\%) compared to liposomes (6\%), and a variant of this platform was tested for in vivo cancer gene therapy. ${ }^{[252]}$ Meanwhile, Yu et al. showed that intraliposomal free radical polymerization initiated by $2,2^{\prime}$-azobis (2methylpropionamide) dihydrochloride could be used to synthesize thermoresponsive PNIPAM nanogels from $N$-isopropylacrylamide, acrylamide, and a $N, N^{\prime}$-methylenebis-acrylamide crosslinker. An encapsulated indocyanine dye was used to absorb NIR radiation and create a local increase in temperature that could shrink the nanogels and release a co-encapsulated drug payload. ${ }^{[253]}$ Redox-responsive nanogels have also been formulated by using liposomes to template acrylamide crosslinking with $N, N^{\prime}$-dimethacryloyl cystine. A drug payload was fully released from this system with a $24 \mathrm{~h}$ exposure to $10 \mathrm{mM}$ glutathione, compared to $\sim 10 \%$ release from liposomes or non-redox responsive nanogels under the same reducing conditions. $^{[254]}$ Acrylate-based nanogels have also been templated using cell-derived extracellular vesicles and UV irradiation. ${ }^{[255]}$ Overall, nanogels offer a number of opportunities 
in drug delivery by combining the advantageous properties of both nanoscale vectors and hydrogels.

\section{Concluding Remarks}

The vast library of available hydrogelation chemistries has enabled the rational design of natural, synthetic, and semi-synthetic hydrogels with various mechanical and chemical functionalities. In addition, more complex hydrogel interactions have been used to formulate double network, ${ }^{[39]}$ interpenetrating network, ${ }^{[37]}$ and slide-ring hydrogels. ${ }^{[40]}$ Nanoparticle-mediated hydrogelation has recently emerged alongside these mechanisms and has been used to confer shear-thinning behavior ${ }^{[79]}$ and enhanced mechanical ${ }^{[81]}$ or drug-encapsulating properties. ${ }^{[20,21]}$ Despite this versatility, cell-encapsulating hydrogel platforms have not yet been able to fully recapitulate the structure, biology, and dynamics of native tissue. In nature, the role of the extracellular matrix in regulating cell behavior is widely recognized, with interactions between cells and matrix fibers relying on a complex array of biophysical and biochemical cues. ${ }^{[256]}$ The native extracellular matrix is constantly remodeled by cells, whose behavior is in turn affected by these modifications. ${ }^{[257]}$ In this context, the reversible nature of noncovalent interactions or dynamic covalent crosslinking (e.g. Schiff base reaction, oxime or disulfide bonds) may be exploited for the fabrication of adaptable hydrogels able to undergo structural reorganization in response to cell-induced modifications. ${ }^{[258]}$ For example, viscoelastic alginate hydrogels with tunable stress relaxation properties have been designed to mimic the behavior of native tissue in response to applied strain. ${ }^{[259]}$ An alternative strategy is through the rational design of the time-domain in self-assembling networks. ${ }^{[260]}$ As an example, Heinen and Walther demonstrated the tunable delayed onset and disassembly of a low molecular weight gelator. ${ }^{[261]}$ An emerging concept in the soft materials field is the development of adaptive and interacting networks, which are designed to better mimic complex spatiotemporal responses found in biological systems. ${ }^{[262]}$ Furthermore, it is becoming increasingly clear that hydrogel- 
encapsulated cells actively deposit nascent proteins which can significantly alter the nature of the cell-material interface. ${ }^{[263,264]}$ For example, Horton et al. recently showed that mesenchymal stem cells encapsulated in PEG hydrogels secreted fibronectin that enabled cell spreading, even in the absence of any synthetic adhesion moieties. This work and other studies highlight the importance of elucidating these complex mechanistic details, ultimately, with the objective of designing "smart" hydrogel platforms that are more able to dictate cell-based matrix remodeling and protein secretion. ${ }^{[265]}$

In this Progress Report, we have defined intrinsic triggers as events that initiate gelation by directly altering the base material or reaction kinetics. Intrinsic triggers include alterations in temperature or solution $\mathrm{pH}$, and the input of light or enzymes. Of these methods, enzymecatalyzed hydrogelation offers potentially interesting clinical applications, given that crosslinking can occur under physiological conditions and the prevalence of enzymes as important mediators in many physiological and pathological processes. ${ }^{[102]}$ While certain enzymes have naturally evolved to catalyze a particular biopolymer, these processes can also be adapted to synthetic systems. For example, as well as fibrinogen crosslinking, transglutaminase can be used to catalyze the gelation of other polymers that have been functionalized with lysine and glutamine moieties. Using this approach, different groups have used transglutaminase to catalyze the gelation of elastin-like polypeptide ${ }^{[266]}$ and HA/PEG hydrogels. ${ }^{[267]}$ Non-biological catalysts, such as gold- and platinum-based nanoparticles able to mimic the activity of various enzymes, ${ }^{[268,269]}$ as well as de novo designed enzymes, ${ }^{[270,271]}$ could provide alternative opportunities for triggered hydrogelation. These approaches could expand the operational window of enzymatic crosslinking by allowing gelation to occur under more extreme conditions that would typically denature natural enzymes. There is also great promise when these triggers are combined with the emerging areas of transient and dissipative selfassembly, which could allow for a pre-configured gelation profile based on a single stimulus. 
We have also outlined several indirect trigger mechanisms for hydrogelation, including many approaches whereby crosslinking species are liberated from stimuli-responsive carriers. The modularity and synthetic flexibility of these approaches offer greater opportunity for the design of new trigger mechanisms. For example, the first use of ultrasound as a trigger for enzymatic hydrogelation has only recently been reported, ${ }^{[123]}$ complementing existing systems that are responsive to temperature changes ${ }^{[120]}$ or electromagnetic radiation. ${ }^{[156]}$ Radiofrequency, ${ }^{[272]}$ microwave heating, ${ }^{[273]}$ and X-ray radiation ${ }^{[274]}$ have all been used to release cargo from liposomes for tumor treatment, but to the best of our knowledge, these methods have not been used to release reactive components capable of triggering gelation. Similarly, alternating magnetic fields have been used to remotely heat magnetic nanoparticles, yet there are only limited examples in which this has been used to trigger gelation. Notably, Lee et al. used magnetically-induced heating of superparamagnetic iron oxide nanoparticles to trigger the gelation of PEGDA in the presence of a thermal initiator. ${ }^{[275]}$ Furthermore, while magneticallyresponsive liposomes incorporating maghemite nanocrystals or iron oxide nanoparticles have been used to release drugs under applied magnetic fields, ${ }^{[276,277]}$ such carriers have not yet been used for triggered gelation. Another underexplored trigger mechanism is mechanical forces, even though shear-sensitive liposomes have been developed for drug release. ${ }^{[278]}$ It is therefore feasible that these stimuli-responsive systems could be adapted and used for triggered hydrogelation.

Overall, we anticipate that the emergence of novel hydrogelation mechanisms, as well as the reconfiguration of existing triggers, will enable new opportunities in biomaterial science and propel the development of new biomedical applications. This is particularly important for the clinical translation of hydrogel-based carriers, implants, and devices, where the selection of the hydrogel base material, hydrogelation mechanism, and trigger are all highly dependent on the envisaged application and route of administration. Many hydrogel products have reached the 
market, ${ }^{[279]}$ as part of surgical sealants $\left(e . g . \mathrm{COSEAL}^{\circledR}, \mathrm{EVICEL}^{\circledR}\right.$ fibrin sealant, or ReSURE ${ }^{\circledR}$ ocular sealant), ${ }^{[280]}$ wound dressings $\left(\right.$ e.g. Granugel $\left.{ }^{\circledR}\right),{ }^{[281]}$ anti-bacterial coatings (e.g. $\left.\mathrm{DAC}^{\circledR}\right),{ }^{[282]}$ dermal fillers $\left(\right.$ e.g. Restylane $\left.{ }^{\circledR}\right),{ }^{[283]}$ and cartilage repair matrices $\left(e . g . \mathrm{CaReS}^{\circledR}\right) .{ }^{[284]}$ Meanwhile, ongoing and future clinical trials are testing injectable hydrogel formulations for the treatment of knee osteoarthritis ${ }^{[285,286]}$ and cartilage defects, ${ }^{[287]}$ antibiotic-loaded hydrogel coatings for hip implants, ${ }^{[288]}$ and tissue-marking hydrogels for radiotherapy. ${ }^{[289]}$ However, many clinical challenges remain, particularly surrounding scale-up costs, conformity to good manufacturing processes, and complex regulatory and approval procedures. ${ }^{[279]}$ In light of these considerations, hydrogel products with a simple design and based on materials already in use in the clinic may benefit from a more straightforward bench-to-bedside translation and the delivery of real patient benefit. ${ }^{[290]}$

\section{Acknowledgments}

V.N. acknowledges support from the Ermenegildo Zegna Founder's Scholarship program. V.N. and M.M.S. acknowledge support from the Rosetrees Trust. J.P.K.A. was funded by the Medical Research Council (MR/S00551X/1). J.P.W. and M.M.S. were funded by the grant from the UK Regenerative Medicine Platform "Acellular / Smart Materials - 3D Architecture" (MR/R015651/1) and the Engineering and Physical Science Research Council (EPSRC) grant "Bio-functionalised nanomaterials for ultrasensitive biosensing" (EP/K020641/1). M.M.S. 
acknowledges support from a Wellcome Trust Senior Investigator Award (098411/Z/12/Z). The authors thank Dr Liliang Ouyang for his insight and feedback on hydrogel biofabrication.

Received: ((will be filled in by the editorial staff))

Revised: ((will be filled in by the editorial staff)) Published online: ((will be filled in by the editorial staff))

\section{References}

[1] A. D. McNaught, A. Wilkinson, IUPAC. Compendium of Chemical Terminology, 2nd Ed. (the "Gold Book”), Blackwell Scientific Publications, Oxford, 1997.

[2] C. D. Spicer, Polym. Chem. 2020, 11, 184.

[3] S. Van Vlierberghe, P. Dubruel, E. Schacht, Biomacromolecules 2011, 12, 1387.

[4] O. Wichterle, D. Lìm, Nature 1960, 185, 117.

[5] D. Seliktar, Science 2012, 336, 1124 LP.

[6] N. Annabi, A. Tamayol, J. A. Uquillas, M. Akbari, L. E. Bertassoni, C. Cha, G. CamciUnal, M. R. Dokmeci, N. A. Peppas, A. Khademhosseini, Adv. Mater. 2013, 26, 85.

[7] M. F. Maitz, U. Freudenberg, M. V Tsurkan, M. Fischer, T. Beyrich, C. Werner, Nat. Commun. 2013, 4, 2168.

[8] N. Huebsch, E. Lippens, K. Lee, M. Mehta, S. T. Koshy, M. C. Darnell, R. M. Desai, C. M. Madl, M. Xu, X. Zhao, O. Chaudhuri, C. Verbeke, W. S. Kim, K. Alim, A. Mammoto, D. E. Ingber, G. N. Duda, D. J. Mooney, Nat. Mater. 2015, 14, 1269.

[9] D.-S. Shin, J. You, A. Rahimian, T. Vu, C. Siltanen, A. Ehsanipour, G. Stybayeva, J. Sutcliffe, A. Revzin, Angew. Chemie Int. Ed. 2014, 53, 8221.

[10] D. Steinhilber, T. Rossow, S. Wedepohl, F. Paulus, S. Seiffert, R. Haag, Angew. Chemie Int. Ed. 2013, 52, 13538. 
[11] A. J. Kuijpers, G. H. M. Engbers, J. Feijen, S. C. De Smedt, T. K. L. Meyvis, J. Demeester, J. Krijgsveld, S. A. J. Zaat, J. Dankert, Macromolecules 1999, 32, 3325.

[12] M. Patenaude, N. M. B. Smeets, T. Hoare, Macromol. Rapid Commun. 2014, 35, 598.

[13] D. A. Ossipov, J. Hilborn, Macromolecules 2006, 39, 1709.

[14] N. J. Agard, J. A. Prescher, C. R. Bertozzi, J. Am. Chem. Soc. 2004, 126, 15046.

[15] B. D. Mather, K. Viswanathan, K. M. Miller, T. E. Long, Prog. Polym. Sci. 2006, 31, 487.

[16] A. B. Lowe, Polym. Chem. 2014, 5, 4820.

[17] M. Gregoritza, F. P. Brandl, Eur. J. Pharm. Biopharm. 2015, 97, 438.

[18] B. Gyarmati, Á. Némethy, A. Szilágyi, Eur. Polym. J. 2013, 49, 1268.

[19] J. Xu, Y. Liu, S.-H. Hsu, Molecules 2019, 24, 3005.

[20] Y. Liang, K. L. Kiick, Biomacromolecules 2016, 17, 601.

[21] Y. Sekine, Y. Moritani, T. Ikeda-Fukazawa, Y. Sasaki, K. Akiyoshi, Adv. Healthc. Mater. 2012, 1,722 .

[22] R. Messing, N. Frickel, L. Belkoura, R. Strey, H. Rahn, S. Odenbach, A. M. Schmidt, Macromolecules 2011, 44, 2990.

[23] R. Barbucci, D. Pasqui, G. Giani, M. De Cagna, M. Fini, R. Giardino, A. Atrei, Soft Matter 2011, 7, 5558.

[24] I. Braccini, S. Pérez, Biomacromolecules 2001, 2, 1089.

[25] C. H. Yang, M. X. Wang, H. Haider, J. H. Yang, J.-Y. Sun, Y. M. Chen, J. Zhou, Z. Suo, ACS Appl. Mater. Interfaces 2013, 5, 10418.

[26] J. Nie, Z. Wang, Q. Hu, Sci. Rep. 2016, 6, 36005.

[27] D. Gawkowska, J. Cybulska, A. Zdunek, Polymers (Basel). 2018, 10, 762.

[28] H. Dong, J. F. Snyder, K. S. Williams, J. W. Andzelm, Biomacromolecules 2013, 14, 3338. 
[29] U. T. D. Huynh, O. Chambin, A. M. du Poset, A. Assifaoui, Carbohydr. Polym. 2018, $190,121$.

[30] M. A. Cohen Stuart, B. Hofs, I. K. Voets, A. de Keizer, Curr. Opin. Colloid Interface Sci. 2005, 10, 30 .

[31] J. N. Hunt, K. E. Feldman, N. A. Lynd, J. Deek, L. M. Campos, J. M. Spruell, B. M. Hernandez, E. J. Kramer, C. J. Hawker, Adv. Mater. 2011, 23, 2327.

[32] I. A. van Hees, P. J. M. Swinkels, R. G. Fokkink, A. H. Velders, I. K. Voets, J. van der Gucht, M. Kamperman, Polym. Chem. 2019, 10, 3127.

[33] A. P. Nowak, V. Breedveld, L. Pakstis, B. Ozbas, D. J. Pine, D. Pochan, T. J. Deming, Nature 2002, 417, 424.

[34] N. M. Sangeetha, U. Maitra, Chem. Soc. Rev. 2005, 34, 821.

[35] L. A. Estroff, A. D. Hamilton, Chem. Rev. 2004, 104, 1201.

[36] M. A. Greenfield, J. R. Hoffman, M. Olvera de la Cruz, S. I. Stupp, Langmuir 2010, 26, 3641.

[37] S. Naficy, S. Kawakami, S. Sadegholvaad, M. Wakisaka, G. M. Spinks, J. Appl. Polym. Sci. 2013, 130, 2504.

[38] M. A. Haque, T. Kurokawa, J. P. Gong, Polymer (Guildf). 2012, 53, 1805.

[39] J.-Y. Sun, X. Zhao, W. R. K. Illeperuma, O. Chaudhuri, K. H. Oh, D. J. Mooney, J. J. Vlassak, Z. Suo, Nature 2012, 489, 133.

[40] X. Tong, F. Yang, Adv. Mater. 2016, 28, 7257.

[41] A. Hayashi, S.-C. Oh, Agric. Biol. Chem. 1983, 47, 1711.

[42] E. Fernández, D. López, C. Mijangos, M. Duskova-Smrckova, M. Ilavsky, K. Dusek, J. Polym. Sci. Part B Polym. Phys. 2008, 46, 322.

[43] E. R. Draper, D. J. Adams, Chem 2017, 3, 390.

[44] D. Roy, W. L. A. Brooks, B. S. Sumerlin, Chem. Soc. Rev. 2013, 42, 7214. 
[45] Q. Zhang, C. Weber, U. S. Schubert, R. Hoogenboom, Mater. Horizons 2017, 4, 109.

[46] M. A. Ward, T. K. Georgiou, Polymers (Basel). 2011, 3.

[47] H. J. Moon, D. Y. Ko, M. H. Park, M. K. Joo, B. Jeong, Chem. Soc. Rev. 2012, 41, 4860.

[48] S. Y. Kim, H. J. Kim, K. E. Lee, S. S. Han, Y. S. Sohn, B. Jeong, Macromolecules 2007, $40,5519$.

[49] A. P. Constantinou, T. K. Georgiou, Polym. Chem. 2016, 7, 2045.

[50] A. P. Constantinou, N. F. Sam-Soon, D. R. Carroll, T. K. Georgiou, Macromolecules 2018, 51, 7019 .

[51] J. Lee, Y. H. Bae, Y. S. Sohn, B. Jeong, Biomacromolecules 2006, 7, 1729.

[52] M. Luzon, C. Boyer, C. Peinado, T. Corrales, M. Whittaker, L. Tao, T. P. Davis, J. Polym. Sci. Part A Polym. Chem. 2010, 48, 2783.

[53] A. Parisi-Amon, W. Mulyasasmita, C. Chung, S. C. Heilshorn, Adv. Healthc. Mater. 2013, 2, 428 .

[54] Y.-J. Hwang, J. Granelli, J. Lyubovitsky, ACS Appl. Mater. Interfaces 2012, 4, 261.

[55] S. Van Vlierberghe, J. Mater. Sci. 2016, 51, 4349.

[56] S. A. Sell, M. P. Francis, K. Garg, M. J. McClure, D. G. Simpson, G. L. Bowlin, Biomed. Mater. 2008, 3, 45001.

[57] E. Mirzaei B., A. Ramazani S. A., M. Shafiee, M. Danaei, Int. J. Polym. Mater. Polym. Biomater. 2013, 62, 605.

[58] C. A. DeForest, B. D. Polizzotti, K. S. Anseth, Nat. Mater. 2009, 8, 659.

[59] Y. Jiang, J. Chen, C. Deng, E. J. Suuronen, Z. Zhong, Biomaterials 2014, 35, 4969.

[60] L. J. Smith, S. M. Taimoory, R. Y. Tam, A. E. G. Baker, N. Binth Mohammad, J. F. Trant, M. S. Shoichet, Biomacromolecules 2018, 19, 926.

[61] C. M. Madl, S. C. Heilshorn, Chem. Mater. 2019, 31, 8035.

[62] D. L. Alge, M. A. Azagarsamy, D. F. Donohue, K. S. Anseth, Biomacromolecules 2013, 
$14,949$.

[63] S. T. Koshy, R. M. Desai, P. Joly, J. Li, R. K. Bagrodia, S. A. Lewin, N. S. Joshi, D. J. Mooney, Adv. Healthc. Mater. 2016, 5, 541.

[64] R. M. Desai, S. T. Koshy, S. A. Hilderbrand, D. J. Mooney, N. S. Joshi, Biomaterials $\mathbf{2 0 1 5}, 50,30$.

[65] V. Delplace, P. E. B. Nickerson, A. Ortin-Martinez, A. E. G. Baker, V. A. Wallace, M. S. Shoichet, Adv. Funct. Mater. 2020, 30, 1903978.

[66] A. Famili, K. Rajagopal, Mol. Pharm. 2017, 14, 1961.

[67] V. X. Truong, K. Zhou, G. P. Simon, J. S. Forsythe, Macromol. Rapid Commun. 2015, $36,1729$.

[68] D. P. Nair, M. Podgórski, S. Chatani, T. Gong, W. Xi, C. R. Fenoli, C. N. Bowman, Chem. Mater. 2014, 26, 724.

[69] E. A. Phelps, N. O. Enemchukwu, V. F. Fiore, J. C. Sy, N. Murthy, T. A. Sulchek, T. H. Barker, A. J. García, Adv. Mater. 2012, 24, 64.

[70] C. J. Higginson, S. Y. Kim, M. Peláez-Fernández, A. Fernández-Nieves, M. G. Finn, J. Am. Chem. Soc. 2015, 137, 4984.

[71] V. X. Truong, I. Donderwinkel, J. E. Frith, J. Polym. Sci. Part A Polym. Chem. 2019, 57, 1872.

[72] T.-W. Chu, J. Feng, J. Yang, J. Kopeček, J. Control. Release 2015, 220, 608.

[73] C. Li, P. Chen, Y. Shao, X. Zhou, Y. Wu, Z. Yang, Z. Li, T. Weil, D. Liu, Small 2015, $11,1138$.

[74] S. J. de Jong, B. van Eerdenbrugh, C. F. van Nostrum, J. J. Kettenes-van den Bosch, W. E. Hennink, J. Control. Release 2001, 71, 261.

[75] S. M. Mantooth, B. G. Munoz-Robles, M. J. Webber, Macromol. Biosci. 2019, 19, 1800281. 
[76] G. Liu, Q. Yuan, G. Hollett, W. Zhao, Y. Kang, J. Wu, Polym. Chem. 2018, 9, 3436.

[77] E. A. Appel, F. Biedermann, U. Rauwald, S. T. Jones, J. M. Zayed, O. A. Scherman, J. Am. Chem. Soc. 2010, 132, 14251.

[78] E. A. Appel, M. W. Tibbitt, M. J. Webber, B. A. Mattix, O. Veiseh, R. Langer, Nat. Commun. 2015, 6, 6295.

[79] E. A. Appel, M. W. Tibbitt, J. M. Greer, O. S. Fenton, K. Kreuels, D. G. Anderson, R. Langer, ACS Macro Lett. 2015, 4, 848.

[80] S. Xu, L. Yin, Y. Xiang, H. Deng, L. Deng, H. Fan, H. Tang, J. Zhang, A. Dong, Macromol. Biosci. 2016, 16, 1188.

[81] J. Yu, W. Ha, J. Sun, Y. Shi, ACS Appl. Mater. Interfaces 2014, 6, 19544.

[82] M. Zhu, K. Wei, S. Lin, X. Chen, C.-C. Wu, G. Li, L. Bian, Small 2018, 14, 1702288.

[83] T. Yata, Y. Takahashi, M. Tan, H. Nakatsuji, S. Ohtsuki, T. Murakami, H. Imahori, Y. Umeki, T. Shiomi, Y. Takakura, M. Nishikawa, Biomaterials 2017, 146, 136.

[84] Q. Li, D. G. Barrett, P. B. Messersmith, N. Holten-Andersen, ACS Nano 2016, 10, 1317.

[85] S. Morozova, M. Muthukumar, J. Chem. Phys. 2018, 149, 163333.

[86] M. Achilli, D. Mantovani, Polymers (Basel). 2010, 2.

[87] N. Rajan, J. Habermehl, M.-F. Coté, C. J. Doillon, D. Mantovani, Nat. Protoc. 2006, 1, 2753.

[88] P. Lundberg, N. A. Lynd, Y. Zhang, X. Zeng, D. V Krogstad, T. Paffen, M. Malkoch, A. M. Nyström, C. J. Hawker, Soft Matter 2013, 9, 82.

[89] M. Fleischer, C. Schmuck, Chem. Commun. 2014, 50, 10464.

[90] F. Lin, J. Yu, W. Tang, J. Zheng, A. Defante, K. Guo, C. Wesdemiotis, M. L. Becker, Biomacromolecules 2013, 14, 3749.

[91] J. Boekhoven, J. M. Poolman, C. Maity, F. Li, L. van der Mee, C. B. Minkenberg, E. Mendes, J. H. van Esch, R. Eelkema, Nat. Chem. 2013, 5, 433. 
[92] D. J. Adams, M. F. Butler, W. J. Frith, M. Kirkland, L. Mullen, P. Sanderson, Soft Matter 2009, 5, 1856.

[93] A. Ferrini, M. M. Stevens, S. Sattler, N. Rosenthal, Front. Cardiovasc. Med. 2019, 6, 26.

[94] W. Zhang, R. Wang, Z. Sun, X. Zhu, Q. Zhao, T. Zhang, A. Cholewinski, F. (Kuo) Yang, B. Zhao, R. Pinnaratip, P. K. Forooshani, B. P. Lee, Chem. Soc. Rev. 2020, 49, 433.

[95] B. P. Lee, J. L. Dalsin, P. B. Messersmith, Biomacromolecules 2002, 3, 1038.

[96] D. G. Barrett, G. G. Bushnell, P. B. Messersmith, Adv. Healthc. Mater. 2013, 2, 745.

[97] Y. J. Xu, K. Wei, P. Zhao, Q. Feng, C. K. K. Choi, L. Bian, Biomater. Sci. 2016, 4, 1726.

[98] B. J. Kim, D. X. Oh, S. Kim, J. H. Seo, D. S. Hwang, A. Masic, D. K. Han, H. J. Cha, Biomacromolecules 2014, 15, 1579.

[99] S. Hong, K. Yang, B. Kang, C. Lee, I. T. Song, E. Byun, K. I. Park, S.-W. Cho, H. Lee, Adv. Funct. Mater. 2013, 23, 1774.

[100] J. H. Cho, J. S. Lee, J. Shin, E. J. Jeon, S. An, Y. S. Choi, S.-W. Cho, Adv. Funct. Mater. 2018, 28, 1705244.

[101] Q. Zhao, S. Mu, Y. Long, J. Zhou, W. Chen, D. Astruc, C. Gaidau, H. Gu, Macromol. Mater. Eng. 2019, 304, 1800664.

[102] L. S. Moreira Teixeira, J. Feijen, C. A. van Blitterswijk, P. J. Dijkstra, M. Karperien, Biomaterials 2012, 33, 1281.

[103] T. Su, Z. Tang, H. He, W. Li, X. Wang, C. Liao, Y. Sun, Q. Wang, Chem. Sci. 2014, 5, 4204.

[104] A. Herchenhan, F. Uhlenbrock, P. Eliasson, M. Weis, D. Eyre, K. E. Kadler, S. P. Magnusson, M. Kjaer, J. Biol. Chem. 2015, 290, 16440.

[105] E. L. Bakota, L. Aulisa, K. M. Galler, J. D. Hartgerink, Biomacromolecules 2011, 12, 82. 
[106] W. S. Toh, T. C. Lim, M. Kurisawa, M. Spector, Biomaterials 2012, 33, 3835.

[107] K. Ren, C. He, C. Xiao, G. Li, X. Chen, Biomaterials 2015, 51, 238.

[108] D. Wang, X. Yang, Q. Liu, L. Yu, J. Ding, J. Mater. Chem. B 2018, 6, 6067.

[109] L.-S. Wang, J. E. Chung, P. Pui-Yik Chan, M. Kurisawa, Biomaterials 2010, 31, 1148.

[110] J. Carthew, J. E. Frith, J. S. Forsythe, V. X. Truong, J. Mater. Chem. B 2018, 6, 1394.

[111] T. E. Brown, K. S. Anseth, Chem. Soc. Rev. 2017, 46, 6532.

[112] J. L. Ifkovits, J. A. Burdick, Tissue Eng. 2007, 13, 2369.

[113] W. M. Gramlich, J. L. Holloway, R. Rai, J. A. Burdick, Nanotechnology 2013, 25, 14004.

[114] H. Lee, S. Chung, M.-G. Kim, L. P. Lee, J. Y. Lee, Adv. Healthc. Mater. 2016, 5, 1638.

[115] P. E. Farahani, S. M. Adelmund, J. A. Shadish, C. A. DeForest, J. Mater. Chem. B 2017, $5,4435$.

[116] E. Rideau, R. Dimova, P. Schwille, F. R. Wurm, K. Landfester, Chem. Soc. Rev. 2018, $47,8572$.

[117] V. Nele, M. N. Holme, U. Kauscher, M. R. Thomas, J. J. Doutch, M. M. Stevens, Langmuir 2019, 35, 6064.

[118] S. Mura, J. Nicolas, P. Couvreur, Nat. Mater. 2013, 12, 991.

[119] Z. Al-Ahmady, K. Kostarelos, Chem. Rev. 2016, 116, 3883.

[120] E. Westhaus, P. B. Messersmith, Biomaterials 2001, 22, 453.

[121] T. J. Sanborn, P. B. Messersmith, A. E. Barron, Biomaterials 2002, 23, 2703.

[122] C. C. Coussios, R. A. Roy, Annu. Rev. Fluid Mech. 2008, 40, 395.

[123] V. Nele, C. E. Schutt, J. P. Wojciechowski, W. Kit-Anan, J. J. Doutch, J. P. K. Armstrong, M. M. Stevens, Adv. Mater. 2020, 1905914.

[124] S. M. Graham, R. Carlisle, J. J. Choi, M. Stevenson, A. R. Shah, R. S. Myers, K. Fisher, M.-B. Peregrino, L. Seymour, C. C. Coussios, J. Control. Release 2014, 178, 101.

[125] N. Hijnen, S. Langereis, H. Grüll, Adv. Drug Deliv. Rev. 2014, 72, 65. 
[126] S. R. Sirsi, M. A. Borden, Adv. Drug Deliv. Rev. 2014, 72, 3.

[127] G. D. Pangu, K. P. Davis, F. S. Bates, D. A. Hammer, Macromol. Biosci. 2010, 10, 546.

[128] U. Kauscher, M. N. Holme, M. Björnmalm, M. M. Stevens, Adv. Drug Deliv. Rev. 2018.

[129] S. Ibsen, C. E. Schutt, S. Esener, Drug Des. Devel. Ther. 2013, 7, 375.

[130] N. Rapoport, Wiley Interdiscip. Rev. Nanomedicine Nanobiotechnology 2012, 4, 492.

[131] S. Mo, C.-C. Coussios, L. Seymour, R. Carlisle, Expert Opin. Drug Deliv. 2012, 9, 1525.

[132] A. Schroeder, J. Kost, Y. Barenholz, Chem. Phys. Lipids 2009, 162, 1.

[133] G. ter Haar, C. Coussios, Int. J. Hyperth. 2007, 23, 89.

[134] E. R. Ruskowitz, C. A. DeForest, Nat. Rev. Mater. 2018, 3, 17087.

[135] K. T. Nguyen, J. L. West, Biomaterials 2002, 23, 4307.

[136] J. Zhang, P. Xiao, C. Dietlin, D. Campolo, F. Dumur, D. Gigmes, F. Morlet-Savary, J.P. Fouassier, J. Lalevée, Macromol. Chem. Phys. 2016, 217, 1214.

[137] Q. T. Nguyen, Y. Hwang, A. C. Chen, S. Varghese, R. L. Sah, Biomaterials 2012, 33, 6682.

[138] J. W. Nichol, S. T. Koshy, H. Bae, C. M. Hwang, S. Yamanlar, A. Khademhosseini, Biomaterials 2010, 31, 5536.

[139] L. Bian, M. Guvendiren, R. L. Mauck, J. A. Burdick, Proc. Natl. Acad. Sci. 2013, 110, 10117 LP

[140] T.-U. Nguyen, K. E. Watkins, V. Kishore, J. Biomed. Mater. Res. Part A 2019, 107, 1541.

[141] A. D. Rouillard, C. M. Berglund, J. Y. Lee, W. J. Polacheck, Y. Tsui, L. J. Bonassar, B. J. Kirby, Tissue Eng. Part C Methods 2010, 17, 173.

[142] B. G. Amsden, A. Sukarto, D. K. Knight, S. N. Shapka, Biomacromolecules 2007, 8, 3758.

[143] J. Hu, Y. Hou, H. Park, B. Choi, S. Hou, A. Chung, M. Lee, Acta Biomater. 2012, 8, 
1730.

[144] C. N. Bowman, C. J. Kloxin, AIChE J. 2008, 54, 2775.

[145] B. D. Fairbanks, M. P. Schwartz, A. E. Halevi, C. R. Nuttelman, C. N. Bowman, K. S. Anseth, Adv. Mater. 2009, 21, 5005.

[146] S. C. Skaalure, S. Chu, S. J. Bryant, Adv. Healthc. Mater. 2015, 4, 420.

[147] Z. Mũnoz, H. Shih, C.-C. Lin, Biomater. Sci. 2014, 2, 1063.

[148] W. M. Gramlich, I. L. Kim, J. A. Burdick, Biomaterials 2013, 34, 9803.

[149] S. Wu, J. P. Blinco, C. Barner-Kowollik, Chem. - A Eur. J. 2017, 23, 8325.

[150] Z. L. Rodgers, R. M. Hughes, L. M. Doherty, J. R. Shell, B. P. Molesky, A. M. Brugh, M. D. E. Forbes, A. M. Moran, D. S. Lawrence, J. Am. Chem. Soc. 2015, 137, 3372.

[151] V. X. Truong, K. M. Tsang, F. Ercole, J. S. Forsythe, Chem. Mater. 2017, 29, 3678.

[152] K. Gwon, E.-J. Jo, A. Sahu, J. Y. Lee, M.-G. Kim, G. Tae, Mater. Sci. Eng. C 2018, 90, 77.

[153] L. Viitala, S. Pajari, T. Lajunen, L.-S. Kontturi, T. Laaksonen, P. Kuosmanen, T. Viitala, A. Urtti, L. Murtomäki, Langmuir 2016, 32, 4554.

[154] T. S. Troutman, S. J. Leung, M. Romanowski, Adv. Mater. 2009, 21, 2334.

[155] A. K. Rengan, A. B. Bukhari, A. Pradhan, R. Malhotra, R. Banerjee, R. Srivastava, A. De, Nano Lett. 2015, 15, 842.

[156] R. S. Stowers, S. C. Allen, L. J. Suggs, Proc. Natl. Acad. Sci. 2015, 112, 1953 LP.

[157] T. Lajunen, R. Nurmi, L. Kontturi, L. Viitala, M. Yliperttula, L. Murtomäki, A. Urtti, J. Control. Release 2016, 244, 157.

[158] Z.-Y. Zhang, P. Shum, M. Yates, P. B. Messersmith, D. H. Thompson, Bioconjug. Chem. 2002, 13, 640 .

[159] Y. Qiu, K. Park, Adv. Drug Deliv. Rev. 2012, 64, 49.

[160] L. Hu, Q. Zhang, X. Li, M. J. Serpe, Mater. Horizons 2019, 6, 1774. 
[161] M. Cianchetti, C. Laschi, A. Menciassi, P. Dario, Nat. Rev. Mater. 2018, 3, 143.

[162] I. Pastoriza-Santos, C. Kinnear, J. Pérez-Juste, P. Mulvaney, L. M. Liz-Marzán, Nat. Rev. Mater. 2018, 3, 375.

[163] H. R. Culver, J. R. Clegg, N. A. Peppas, Acc. Chem. Res. 2017, 50, 170.

[164] Z. Liu, M. Tang, J. Zhao, R. Chai, J. Kang, Adv. Mater. 2018, 30, 1705388.

[165] S. R. Caliari, J. A. Burdick, Nat. Methods 2016, 13, 405.

[166] M. J. Kratochvil, A. J. Seymour, T. L. Li, S. P. Paşca, C. J. Kuo, S. C. Heilshorn, Nat. Rev. Mater. 2019, 4, 606.

[167] M. A. Schwartz, C. S. Chen, Science 2013, 339, 402 LP.

[168] L. G. Griffith, M. A. Swartz, Nat. Rev. Mol. Cell Biol. 2006, 7, 211.

[169] J. J. Green, J. H. Elisseeff, Nature 2016, 540, 386.

[170] E. Prince, E. Kumacheva, Nat. Rev. Mater. 2019, 4, 99.

[171] A. M. Rosales, K. S. Anseth, Nat. Rev. Mater. 2016, 1, 15012.

[172] C. Li, L. Ouyang, I. J. Pence, A. C. Moore, Y. Lin, C. W. Winter, J. P. K. Armstrong, M. M. Stevens, Adv. Mater. 2019, 31, 1900291.

[173] A. K. Jha, A. Mathur, F. L. Svedlund, J. Ye, Y. Yeghiazarians, K. E. Healy, J. Control. Release 2015, 209, 308.

[174] E. T. Pashuck, B. J. R. Duchet, C. S. Hansel, S. A. Maynard, L. W. Chow, M. M. Stevens, ACS Nano 2016, 10, 11096.

[175] A. S. Gobin, J. L. West, FASEB J. 2002, 16, 751.

[176] A. J. Engler, S. Sen, H. L. Sweeney, D. E. Discher, Cell 2006, 126, 677.

[177] N. Huebsch, P. R. Arany, A. S. Mao, D. Shvartsman, O. A. Ali, S. A. Bencherif, J. Rivera-Feliciano, D. J. Mooney, Nat. Mater. 2010, 9, 518.

[178] J. A. Burdick, W. L. Murphy, Nat. Commun. 2012, 3, 1269.

[179] M. Guvendiren, J. A. Burdick, Nat. Commun. 2012, 3, 792. 
[180] C. F. Guimarães, L. Gasperini, A. P. Marques, R. L. Reis, Nat. Rev. Mater. 2020, 5, 351.

[181] S. Khetan, M. Guvendiren, W. R. Legant, D. M. Cohen, C. S. Chen, J. A. Burdick, Nat. Mater. 2013, 12, 458.

[182] P. A. Parmar, S. C. Skaalure, L. W. Chow, J.-P. St-Pierre, V. Stoichevska, Y. Y. Peng, J. A. Werkmeister, J. A. M. Ramshaw, M. M. Stevens, Biomaterials 2016, 99, 56.

[183] C. M. Madl, B. L. LeSavage, R. E. Dewi, C. B. Dinh, R. S. Stowers, M. Khariton, K. J. Lampe, D. Nguyen, O. Chaudhuri, A. Enejder, S. C. Heilshorn, Nat. Mater. 2017, 16, 1233.

[184] C. M. Madl, L. M. Katz, S. C. Heilshorn, ACS Macro Lett. 2018, 7, 1302.

[185] S. R. Eckhouse, B. P. Purcell, J. R. McGarvey, D. Lobb, C. B. Logdon, H. Doviak, J. W. O’Neill, J. A. Shuman, C. P. Novack, K. N. Zellars, S. Pettaway, R. A. Black, A. Khakoo, T. Lee, R. Mukherjee, J. H. Gorman, R. C. Gorman, J. A. Burdick, F. G. Spinale, Sci. Transl. Med. 2014, 6, 223ra21 LP.

[186] J. D. Weaver, D. M. Headen, J. Aquart, C. T. Johnson, L. D. Shea, H. Shirwan, A. J. García, Sci. Adv. 2017, 3, e1700184.

[187] Y. Bu, L. Zhang, G. Sun, F. Sun, J. Liu, F. Yang, P. Tang, D. Wu, Adv. Mater. 2019, 31, 1901580.

[188] M. T. Spang, K. L. Christman, Acta Biomater. 2018, 68, 1.

[189] J. H. Traverse, T. D. Henry, N. Dib, A. N. Patel, C. Pepine, G. L. Schaer, J. A. DeQuach, A. M. Kinsey, P. Chamberlin, K. L. Christman, JACC Basic to Transl. Sci. 2019, 4, 659 LP.

[190] Y. Zhu, N. A. Wood, K. Fok, T. Yoshizumi, D. W. Park, H. Jiang, D. S. Schwartzman, M. A. Zenati, T. Uchibori, W. R. Wagner, C. N. Riviere, Ann. Thorac. Surg. 2016, 102, 780.

[191] B. Sharma, S. Fermanian, M. Gibson, S. Unterman, D. A. Herzka, B. Cascio, J. Coburn, 46 
A. Y. Hui, N. Marcus, G. E. Gold, J. H. Elisseeff, Sci. Transl. Med. 2013, 5, 167ra6 LP.

[192] E. Shirzaei Sani, A. Kheirkhah, D. Rana, Z. Sun, W. Foulsham, A. Sheikhi, A. Khademhosseini, R. Dana, N. Annabi, Sci. Adv. 2019, 5, eaav1281.

[193] Y. Hong, F. Zhou, Y. Hua, X. Zhang, C. Ni, D. Pan, Y. Zhang, D. Jiang, L. Yang, Q. Lin, Y. Zou, D. Yu, D. E. Arnot, X. Zou, L. Zhu, S. Zhang, H. Ouyang, Nat. Commun. 2019, 10, 2060.

[194] N. Annabi, Y.-N. Zhang, A. Assmann, E. S. Sani, G. Cheng, A. D. Lassaletta, A. Vegh, B. Dehghani, G. U. Ruiz-Esparza, X. Wang, S. Gangadharan, A. S. Weiss, A. Khademhosseini, Sci. Transl. Med. 2017, 9, eaai7466.

[195] C. B. Rodell, J. W. MacArthur Jr., S. M. Dorsey, R. J. Wade, L. L. Wang, Y. J. Woo, J. A. Burdick, Adv. Funct. Mater. 2015, 25, 636.

[196] C. B. Rodell, M. E. Lee, H. Wang, S. Takebayashi, T. Takayama, T. Kawamura, J. S. Arkles, N. N. Dusaj, S. M. Dorsey, W. R. T. Witschey, J. J. Pilla, J. H. Gorman 3rd, J. F. Wenk, J. A. Burdick, R. C. Gorman, Circ. Cardiovasc. Interv. 2016, 9, e004058.

[197] L. L. Wang, Y. Liu, J. J. Chung, T. Wang, A. C. Gaffey, M. Lu, C. A. Cavanaugh, S. Zhou, R. Kanade, P. Atluri, E. E. Morrisey, J. A. Burdick, Nat. Biomed. Eng. 2017, 1, 983.

[198] R. K. Avery, H. Albadawi, M. Akbari, Y. S. Zhang, M. J. Duggan, D. V Sahani, B. D. Olsen, A. Khademhosseini, R. Oklu, Sci. Transl. Med. 2016, 8, 365ra156 LP.

[199] Y. Pang, J. Liu, Z. L. Moussa, J. E. Collins, S. McDonnell, A. M. Hayward, K. Jajoo, R. Langer, G. Traverso, Adv. Sci. 2019, 6, 1901041.

[200] C. Li, J. P. K. Armstrong, I. J. Pence, W. Kit-Anan, J. L. Puetzer, S. Correia Carreira, A. C. Moore, M. M. Stevens, Biomaterials 2018, 176, 24.

[201] M. K. Nichols, R. K. Kumar, P. G. Bassindale, L. Tian, A. C. Barnes, B. W. Drinkwater, A. J. Patil, S. Mann, Small 2018, 14, 1800739. 
[202] R. J. Wade, E. J. Bassin, W. M. Gramlich, J. A. Burdick, Adv. Mater. 2015, 27, 1356.

[203] C. A. DeForest, D. A. Tirrell, Nat. Mater. 2015, 14, 523.

[204] K. A. Mosiewicz, L. Kolb, A. J. van der Vlies, M. M. Martino, P. S. Lienemann, J. A. Hubbell, M. Ehrbar, M. P. Lutolf, Nat. Mater. 2013, 12, 1072.

[205] S. A. Fisher, R. Y. Tam, A. Fokina, M. M. Mahmoodi, M. D. Distefano, M. S. Shoichet, Biomaterials 2018, 178, 751.

[206] J. A. Shadish, A. C. Strange, C. A. DeForest, J. Am. Chem. Soc. 2019, 141, 15619.

[207] J. C. Grim, T. E. Brown, B. A. Aguado, D. A. Chapnick, A. L. Viert, X. Liu, K. S. Anseth, ACS Cent. Sci. 2018, 4, 909.

[208] S. C. P. Norris, P. Tseng, A. M. Kasko, ACS Biomater. Sci. Eng. 2016, 2, 1309.

[209] L. Liu, J. A. Shadish, C. K. Arakawa, K. Shi, J. Davis, C. A. DeForest, Adv. Biosyst. 2018, 2, 1800240 .

[210] A. D. Rape, M. Zibinsky, N. Murthy, S. Kumar, Nat. Commun. 2015, 6, 8129.

[211] X. Tong, J. Jiang, D. Zhu, F. Yang, ACS Biomater. Sci. Eng. 2016, 2, 845.

[212] K. M. C. Tsang, N. Annabi, F. Ercole, K. Zhou, D. J. Karst, F. Li, J. M. Haynes, R. A. Evans, H. Thissen, A. Khademhosseini, J. S. Forsythe, Adv. Funct. Mater. 2015, 25, 977.

[213] N. Brandenberg, M. P. Lutolf, Adv. Mater. 2016, 28, 7450.

[214] C. K. Arakawa, B. A. Badeau, Y. Zheng, C. A. DeForest, Adv. Mater. 2017, 29, 1703156.

[215] B. Grigoryan, S. J. Paulsen, D. C. Corbett, D. W. Sazer, C. L. Fortin, A. J. Zaita, P. T. Greenfield, N. J. Calafat, J. P. Gounley, A. H. Ta, F. Johansson, A. Randles, J. E. Rosenkrantz, J. D. Louis-Rosenberg, P. A. Galie, K. R. Stevens, J. S. Miller, Science 2019, 364, 458 LP.

[216] L. Moroni, J. A. Burdick, C. Highley, S. J. Lee, Y. Morimoto, S. Takeuchi, J. J. Yoo, Nat. Rev. Mater. 2018, 3, 21.

[217] L. Ouyang, J. P. K. Armstrong, M. Salmeron-Sanchez, M. M. Stevens, Adv. Funct. Mater. 
2020, 1909009.

[218] W. Bian, N. Bursac, Biomaterials 2009, 30, 1401.

[219] M. L. McCain, A. Agarwal, H. W. Nesmith, A. P. Nesmith, K. K. Parker, Biomaterials 2014, 35, 5462 .

[220] D. E. Heath, A. R. M. Sharif, C. P. Ng, M. G. Rhoads, L. G. Griffith, P. T. Hammond, M. B. Chan-Park, Lab Chip 2015, 15, 2073.

[221] J. Yeh, Y. Ling, J. M. Karp, J. Gantz, A. Chandawarkar, G. Eng, J. Blumling III, R. Langer, A. Khademhosseini, Biomaterials 2006, 27, 5391.

[222] A. D. Graham, S. N. Olof, M. J. Burke, J. P. K. Armstrong, E. A. Mikhailova, J. G. Nicholson, S. J. Box, F. G. Szele, A. W. Perriman, H. Bayley, Sci. Rep. 2017, 7, 7004.

[223] Z. Wang, H. Kumar, Z. Tian, X. Jin, J. F. Holzman, F. Menard, K. Kim, ACS Appl. Mater. Interfaces 2018, 10, 26859.

[224] R. Zhang, N. B. Larsen, Lab Chip 2017, 17, 4273.

[225] J.-F. Xing, M.-L. Zheng, X.-M. Duan, Chem. Soc. Rev. 2015, 44, 5031.

[226] P. N. Bernal, P. Delrot, D. Loterie, Y. Li, J. Malda, C. Moser, R. Levato, Adv. Mater. 2019, 31, 1904209.

[227] A. L. Rutz, K. E. Hyland, A. E. Jakus, W. R. Burghardt, R. N. Shah, Adv. Mater. 2015, 27, 1607.

[228] L. Ouyang, C. B. Highley, W. Sun, J. A. Burdick, Adv. Mater. 2017, 29, 1604983.

[229] L. Ouyang, C. B. Highley, C. B. Rodell, W. Sun, J. A. Burdick, ACS Biomater. Sci. Eng. 2016, $2,1743$.

[230] Z. Chen, D. Zhao, B. Liu, G. Nian, X. Li, J. Yin, S. Qu, W. Yang, Adv. Funct. Mater. 2019, 29, 1900971.

[231] S. Hong, D. Sycks, H. F. Chan, S. Lin, G. P. Lopez, F. Guilak, K. W. Leong, X. Zhao, Adv. Mater. 2015, 27, 4035. 
[232] A. Sydney Gladman, E. A. Matsumoto, R. G. Nuzzo, L. Mahadevan, J. A. Lewis, Nat. Mater. 2016, 15, 413.

[233] C. B. Highley, K. H. Song, A. C. Daly, J. A. Burdick, Adv. Sci. 2019, 6, 1801076.

[234] J. P. K. Armstrong, M. Burke, B. M. Carter, S. A. Davis, A. W. Perriman, Adv. Healthc. Mater. 2016, 5, 1724.

[235] D. B. Kolesky, R. L. Truby, A. S. Gladman, T. A. Busbee, K. A. Homan, J. A. Lewis, Adv. Mater. 2014, 26, 3124.

[236] X. Cui, B. G. Soliman, C. R. Alcala-Orozco, J. Li, M. A. M. Vis, M. Santos, S. G. Wise, R. Levato, J. Malda, T. B. F. Woodfield, J. Rnjak-Kovacina, K. S. Lim, Adv. Healthc. Mater. 2020, 9, 1901667.

[237] L. Ouyang, J. P. K. Armstrong, Q. Chen, Y. Lin, M. M. Stevens, Adv. Funct. Mater. 2020, 30, 1908349.

[238] J. P. Armstrong, A. W. Perriman, Exp. Biol. Med. (Maywood). 2016, 241, 1098.

[239] R. F. Fakhrullin, A. I. Zamaleeva, R. T. Minullina, S. A. Konnova, V. N. Paunov, Chem. Soc. Rev. 2012, 41, 4189.

[240] T. Kamperman, S. Henke, C. W. Visser, M. Karperien, J. Leijten, Small 2017, 13, 1603711.

[241] R. C. Deller, T. Richardson, R. Richardson, L. Bevan, I. Zampetakis, F. Scarpa, A. W. Perriman, Nat. Commun. 2019, 10, 1887.

[242] S. Sakai, M. Taya, ACS Macro Lett. 2014, 3, 972.

[243] Y. Teramura, O. P. Oommen, J. Olerud, J. Hilborn, B. Nilsson, Biomaterials 2013, 34, 2683.

[244] P. Shi, N. Zhao, J. Coyne, Y. Wang, Nat. Commun. 2019, 10, 2223.

[245] A. S. Mao, J.-W. Shin, S. Utech, H. Wang, O. Uzun, W. Li, M. Cooper, Y. Hu, L. Zhang, D. A. Weitz, D. J. Mooney, Nat. Mater. 2017, 16, 236. 
[246] A. S. Mao, B. Özkale, N. J. Shah, K. H. Vining, T. Descombes, L. Zhang, C. M. Tringides, S.-W. Wong, J.-W. Shin, D. T. Scadden, D. A. Weitz, D. J. Mooney, Proc. Natl. Acad. Sci. 2019, 116, 15392 LP.

[247] M. Molina, M. Asadian-Birjand, J. Balach, J. Bergueiro, E. Miceli, M. Calderón, Chem. Soc. Rev. 2015, 44, 6161.

[248] R. T. Chacko, J. Ventura, J. Zhuang, S. Thayumanavan, Adv. Drug Deliv. Rev. 2012, 64, 836.

[249] J. Park, S. H. Wrzesinski, E. Stern, M. Look, J. Criscione, R. Ragheb, S. M. Jay, S. L. Demento, A. Agawu, P. Licona Limon, A. F. Ferrandino, D. Gonzalez, A. Habermann, R. A. Flavell, T. M. Fahmy, Nat. Mater. 2012, 11, 895.

[250] S. Bobone, E. Miele, B. Cerroni, D. Roversi, A. Bocedi, E. Nicolai, A. Di Venere, E. Placidi, G. Ricci, N. Rosato, L. Stella, Langmuir 2015, 31, 7572.

[251] J. N. Lockhart, D. B. Beezer, D. M. Stevens, B. R. Spears, E. Harth, J. Control. Release 2016, 244, 366 .

[252] Z. Chen, F. Liu, Y. Chen, J. Liu, X. Wang, A. T. Chen, G. Deng, H. Zhang, J. Liu, Z. Hong, J. Zhou, Adv. Funct. Mater. 2017, 27, 1703036.

[253] L. Yu, A. Dong, R. Guo, M. Yang, L. Deng, J. Zhang, ACS Biomater. Sci. Eng. 2018, 4, 2424.

[254] J. Ma, H. Deng, F. Zhao, L. Deng, W. Wang, A. Dong, J. Zhang, Macromol. Biosci. 2018, $18,1800049$.

[255] J. Zhang, W. Gao, R. H. Fang, A. Dong, L. Zhang, Small 2015, 11, 4309.

[256] F. M. Watt, W. T. S. Huck, Nat. Rev. Mol. Cell Biol. 2013, 14, 467.

[257] F. Gattazzo, A. Urciuolo, P. Bonaldo, Biochim. Biophys. Acta - Gen. Subj. 2014, 1840, 2506.

[258] H. Wang, S. C. Heilshorn, Adv. Mater. 2015, 27, 3710. 
[259] O. Chaudhuri, L. Gu, D. Klumpers, M. Darnell, S. A. Bencherif, J. C. Weaver, N. Huebsch, H. Lee, E. Lippens, G. N. Duda, D. J. Mooney, Nat. Mater. 2016, 15, 326.

[260] L. Heinen, A. Walther, Soft Matter 2015, 11, 7857.

[261] L. Heinen, T. Heuser, A. Steinschulte, A. Walther, Nano Lett. 2017, 17, 4989.

[262] A. Walther, Adv. Mater. 2019, 1905111.

[263] C. Loebel, R. L. Mauck, J. A. Burdick, Nat. Mater. 2019, 18, 883.

[264] E. R. Horton, Q. Vallmajo-Martin, I. Martin, J. G. Snedeker, M. Ehrbar, U. Blache, Adv. Healthc. Mater. 2020, 1901669.

[265] U. Blache, M. M. Stevens, E. Gentleman, Nat. Biomed. Eng. 2020, DOI 10.1038/s41551019-0500-6.

[266] M. K. McHale, L. A. Setton, A. Chilkoti, Tissue Eng. 2005, 11, 1768.

[267] A. Ranga, M. P. Lutolf, J. Hilborn, D. A. Ossipov, Biomacromolecules 2016, 17, 1553.

[268] C. N. Loynachan, M. R. Thomas, E. R. Gray, D. A. Richards, J. Kim, B. S. Miller, J. C. Brookes, S. Agarwal, V. Chudasama, R. A. McKendry, M. M. Stevens, ACS Nano 2018, $12,279$.

[269] C. N. Loynachan, A. P. Soleimany, J. S. Dudani, Y. Lin, A. Najer, A. Bekdemir, Q. Chen, S. N. Bhatia, M. M. Stevens, Nat. Nanotechnol. 2019, 14, 883.

[270] V. Nanda, R. L. Koder, Nat. Chem. 2010, 2, 15.

[271] P.-S. Huang, S. E. Boyken, D. Baker, Nature 2016, 537, 320.

[272] J. F. Liu, N. Neel, P. Dang, M. Lamb, J. McKenna, L. Rodgers, B. Litt, Z. Cheng, A. Tsourkas, D. Issadore, Small 2018, 14, 1802563.

[273] Y. Jin, X. Liang, Y. An, Z. Dai, Bioconjug. Chem. 2016, 27, 2931.

[274] W. Deng, W. Chen, S. Clement, A. Guller, Z. Zhao, A. Engel, E. M. Goldys, Nat. Commun. 2018, 9, 2713.

[275] H. Lee, G. K. Thirunavukkarasu, S. Kim, J. Y. Lee, Nano Res. 2018, 11, 5997. 
[276] V. Plassat, C. Wilhelm, V. Marsaud, C. Ménager, F. Gazeau, J.-M. Renoir, S. Lesieur, Adv. Funct. Mater. 2011, 21, 83.

[277] E. Amstad, J. Kohlbrecher, E. Müller, T. Schweizer, M. Textor, E. Reimhult, Nano Lett. 2011, 11, 1664.

[278] M. N. Holme, I. A. Fedotenko, D. Abegg, J. Althaus, L. Babel, F. Favarger, R. Reiter, R. Tanasescu, P.-L. Zaffalon, A. Ziegler, B. Müller, T. Saxer, A. Zumbuehl, Nat. Nanotechnol. 2012, 7, 536.

[279] A. Mandal, J. R. Clegg, A. C. Anselmo, S. Mitragotri, Bioeng. Transl. Med. 2020, e10158.

[280] P. Heher, J. Ferguson, H. Redl, P. Slezak, Expert Rev. Med. Devices 2018, 15, 747.

[281] E. Caló, V. V Khutoryanskiy, Eur. Polym. J. 2015, 65, 252.

[282] K. Malizos, M. Blauth, A. Danita, N. Capuano, R. Mezzoprete, N. Logoluso, L. Drago, C. L. Romanò, J. Orthop. Traumatol. Off. J. Ital. Soc. Orthop. Traumatol. 2017, 18, 159.

[283] P. Zhao, W. Zhao, K. Zhang, H. Lin, X. Zhang, J. Appl. Polym. Sci. 2020, 137, 48515.

[284] U. Schneider, L. Rackwitz, S. Andereya, S. Siebenlist, F. Fensky, J. Reichert, I. Löer, T. Barthel, M. Rudert, U. Nöth, Am. J. Sports Med. 2011, 39, 2558.

[285] ClinicalTrials.gov [Internet]. Bethesda (MD): National Library of Medicine (US). Identifier NCT04061733, New Hydroxyethyl Cellulose Hydrogel for the Treatment of the Pain of Knee Arthrosis (PROMGEL-OA); 2019 Aug 20 [cited 2020 May 22]; [about 10 screens]. Available from: https://clinicaltrials.gov/ct2/show/NCT04061733.

[286] ClinicalTrials.gov [Internet]. Bethesda (MD): National Library of Medicine (US). Identifier NCT03897686, Intra-articular Polyacrylamide Hydrogel in Knee Osteoarthritis; 2019 Apr 1 [cited 2020 May 22]; [about 10 screens]. Available from: https://clinicaltrials.gov/ct2/show/NCT03897686. 
[287] ClinicalTrials.gov [Internet]. Bethesda (MD): National Library of Medicine (US). Identifier NCT03262909, Pivotal Study to Evaluate the Safety and Efficacy of GelrinC for Treatment of Cartilage Defects (SAGE); 2017 Aug 25 [cited 2020 May 22]; [about 7 screens]. Available from: https://clinicaltrials.gov/ct2/show/NCT03262909.

[288] ClinicalTrials.gov [Internet]. Bethesda (MD): National Library of Medicine (US). Identifier NCT04251377, Single-stage Surgery With Antibiotic-loaded Hydrogel Coated Implants Versus Two Stage Surgery for Secondary Prevention of Complex Chronic Periprosthetic Hip Joint Infection (SINBIOSE-H); 2020 Jan 31 [cited 2020 May 22]; [about 9 screens]. Available from: https://clinicaltrials.gov/ct2/show/NCT04251377.

[289] ClinicalTrials.gov [Internet]. Bethesda (MD): National Library of Medicine (US). Identifier NCT03713021, TraceIT Tissue Marker to Mark the Primary Resection Bed Margins of Oropharyngeal Cancers; 2018 Oct 19 [cited 2020 May 22]; [about 7 screens]. Available from: https://clinicaltrials.gov/ct2/show/NCT03713021.

[290] A. Ratcliffe, Biomaterials 2011, 32, 4215.

\section{Figures}


A Intrinsic Hydrogelation Triggers

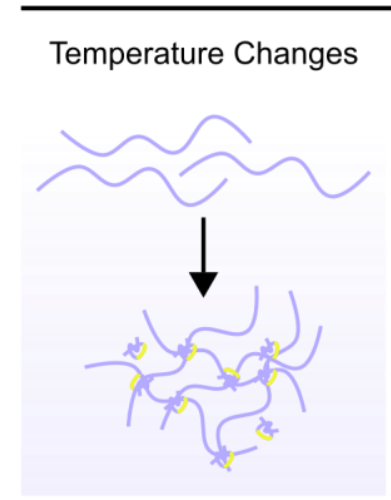

B

$$
\text { Component Mixing }
$$

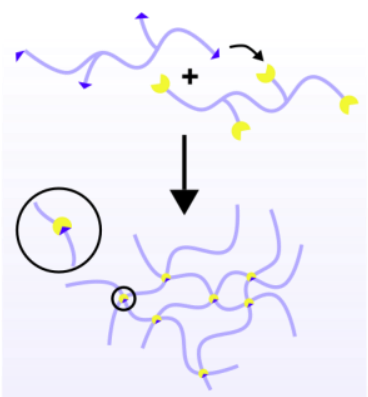

Indirect Hydrogelation Triggers
Change of $\mathrm{pH}$

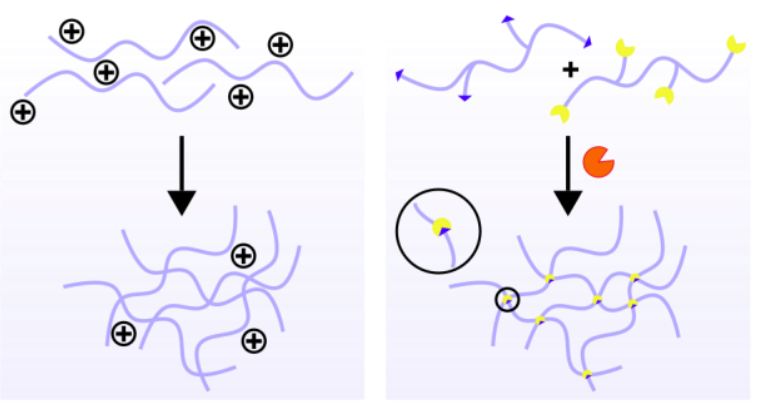

Triggered Activation of Reaction Initiators

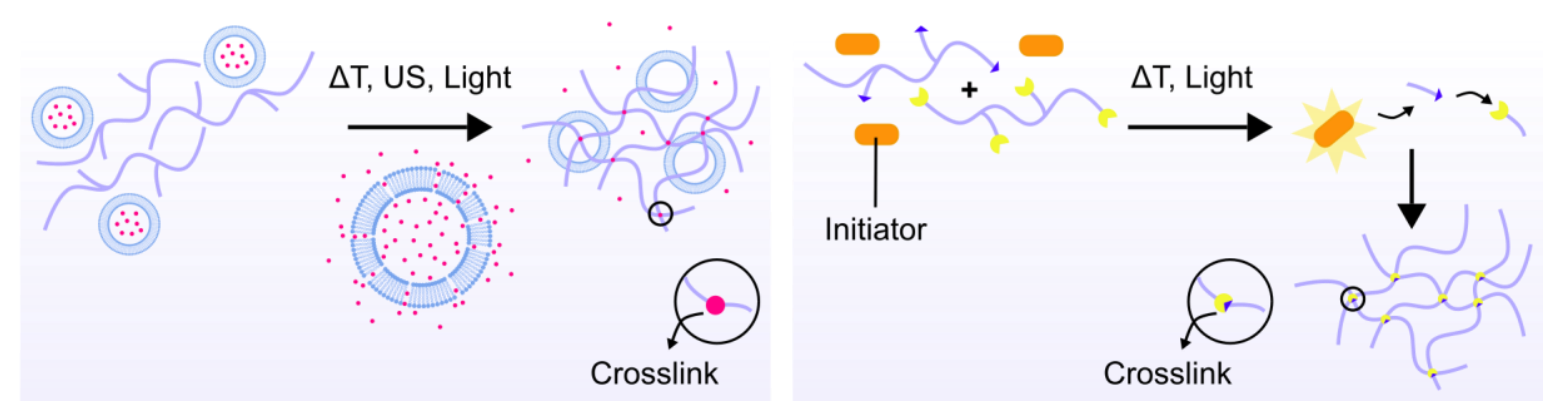

Figure 1. Schematic overview of hydrogelation triggers. (A) Intrinsic triggers include the use of temperature changes, component mixing, $\mathrm{pH}$ changes, and enzyme addition to form network structures. (B) Indirect triggers include the use of stimuli to trigger the release of reactive components from carriers or the activation of thermoinitiators or photoinitiators. 
"Click" Reactions for Hydrogel Crosslinking

Strain-promoted [3+2] Azide-alkyne Cycloaddition

Diels-Alder [4+2] Cycloaddition<smiles>[R]c1ccco1</smiles>

Inverse-electron Demand Diels-Alder Cycloaddition<smiles>[R7]C1=NNC=C2CC1CC([R2])C2C([R7])C</smiles>

Nitrile Oxide-Norbornene Huisgen 1,3-Cycloaddition

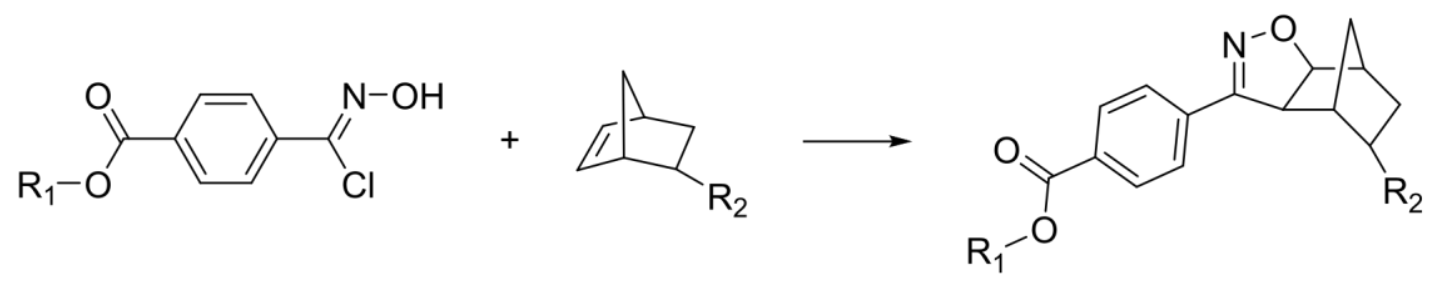

Thiol-ene Michael Addition

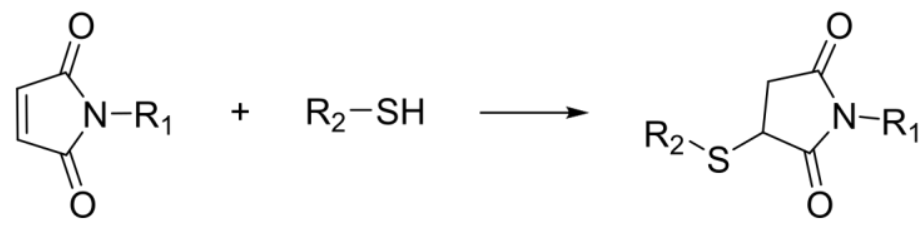

Figure 2. Examples of "click" reactions used for hydrogel crosslinking. "Click" reactions designed for hydrogel crosslinking include the strain-promoted [3+2] azide-alkyne cycloaddition, the Diels-Alder [4+2] cycloaddition, the inverse-electron demand Diels-Alder cycloaddition, the Huisgen 1,3-cycloaddition, and the thiol-ene Michael addition. 
A

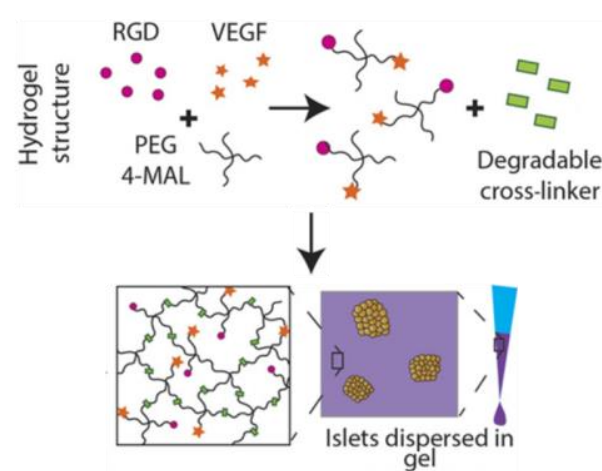

B
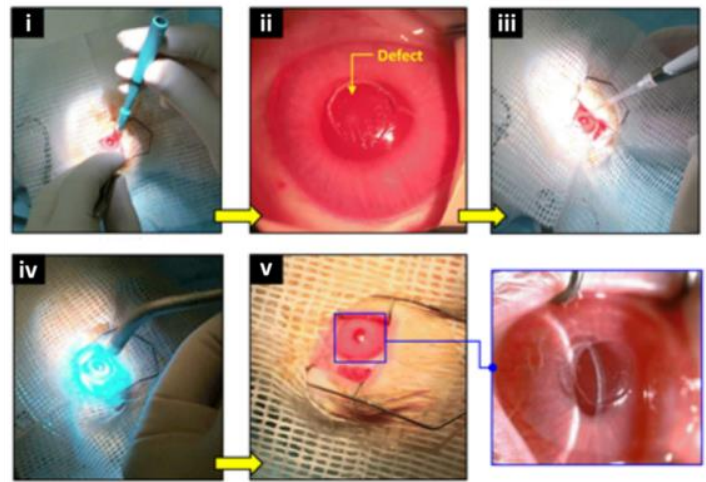

ii)

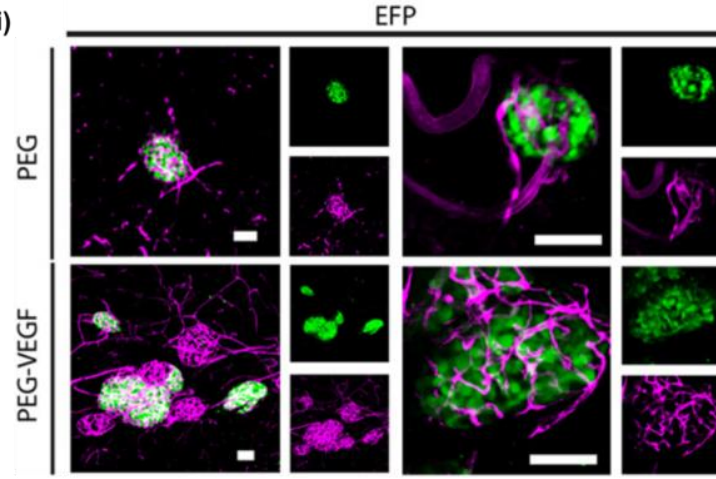

C

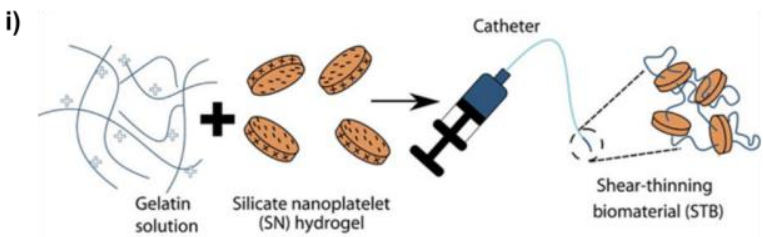

ii)

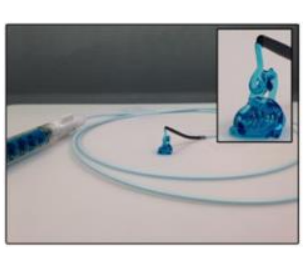

iii)

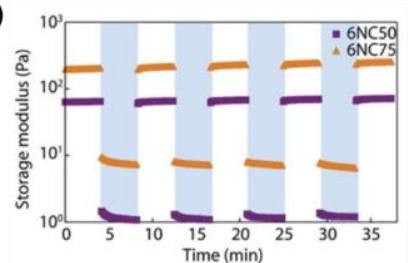

Figure 3. In vivo gelation. (A) (i) Schematic of the PEG-based hydrogel used by Weaver et al. to encapsulate islets for injection into the epididymal fat pad site of C57BL/6J mice. ${ }^{[186]}$ Maleimide-functionalized PEG macromers and thiol-terminated peptide crosslinkers were mixed during injection to form a hydrogel in vivo. (ii) Confocal fluorescence microscopy of the injected islet grafts (shown in green) in the absence or presence of conjugated vascular endothelial growth factor. At the experimental endpoint, the islet grafts were perfused with lectin (magenta), which revealed enhanced islet vascularization for the PEG-VEGF hydrogels. Scale bars: $100 \mu \mathrm{m}$. Reproduced under the terms of the Creative Commons CC-BY-NC license. ${ }^{[186]}$ Copyright 2017, The Authors, published by AAAS. (B) In vivo photocrosslinking of GelMA hydrogels used by Sani et al. for corneal repair in a rabbit model. ${ }^{[192]}$ (i-ii) An incision was performed to create a stromal defect in the rabbit cornea, which was followed by (iii) injection of the hydrogel precursor solution. (iv-v) Photocrosslinking resulted in the formation 
of a transparent hydrogel in the defect site. Reproduced under the terms of the Creative Commons CC-BY-NC license. ${ }^{[192]}$ Copyright 2019, The Authors, published by AAAS. (C) (i) Schematic of a shear-thinning hydrogel obtained upon mixing a gelatin solution with silicate nanoplatelets, as used by Avery et al. for endovascular embolization via catheter injection in murine and porcine models. ${ }^{[198]}$ (ii) Image of the hydrogel injected through a catheter, and (iii) storage modulus of the shear-thinning hydrogel when subjected to intermittent strain (light blue areas). Adapted with permission. Copyright 2016, AAAS. 
A

i)

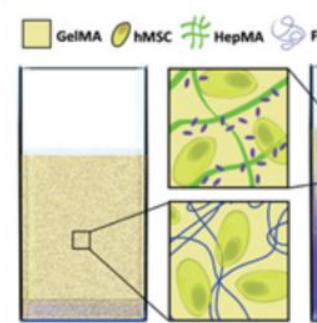

ii)

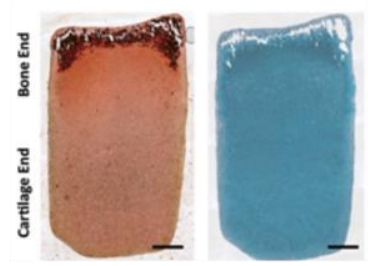

C

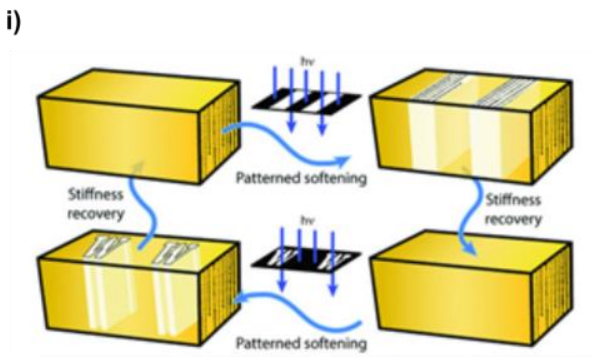

iii)

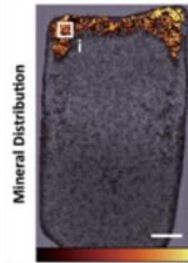

B

i) Standing Waves Trapping of Coacervates Patterned Hydrogel Trapping Device

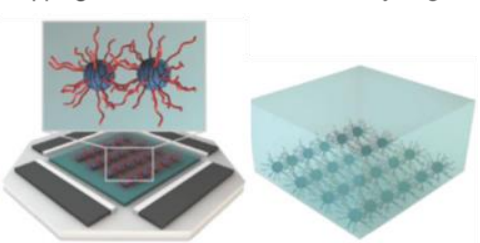

iii)
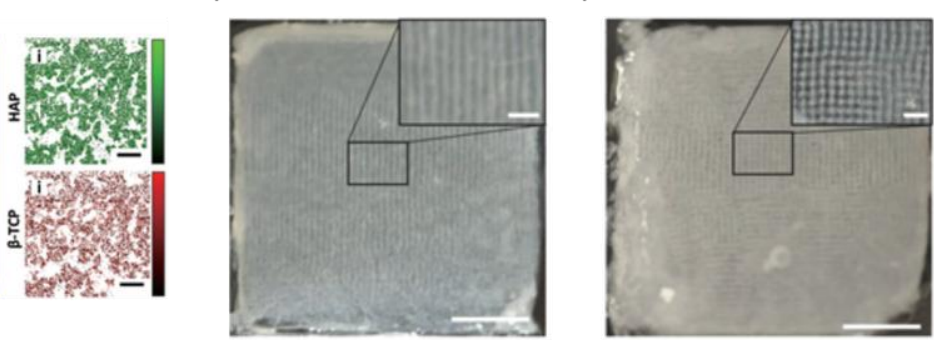

ii)

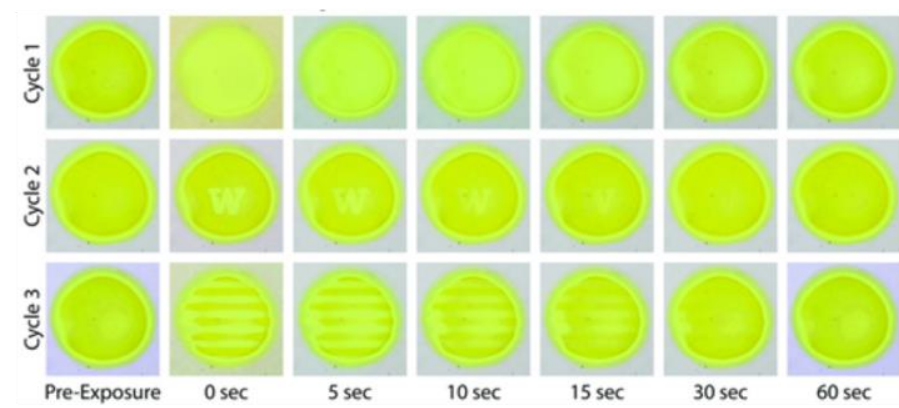

Figure 4. Hydrogel patterning. (A) (i) Schematic of the approach taken by Li et al. for the formation of BMP-2 gradients within GelMA hydrogels. ${ }^{[172]}$ BMP-2 was sequestered by heparin methacrylate (HepMA) with Ficoll $^{\circledR}$ was used as a density modifier to enable gradient formation upon mixing. The hydrogel was photocrosslinked and cultured in osteochondral media for $28 \mathrm{~d}$ to enable the directed differentiation of co-encapsulated human mesenchymal stem cells. The resulting osteochondral tissue was (ii) stained for calcium deposits using Alizarin Red S (red) and sulfated glycosaminoglycans using Alcian Blue (blue), (iii) with Raman spectroscopy used to determine the distribution of hydroxyapatite (HAP) and $\beta$ tricalcium phosphate $(\beta-\mathrm{TCP})$. Reproduced under the terms of the Creative Commons CC-BYNC license. ${ }^{[172]}$ Copyright 2019, The Authors, published by Wiley-VCH Verlag GmbH \& Co. KGaA. B) Schematic of a strategy by Nichols et al. in which acoustic standing waves were used to trap pH-responsive polymer-dipeptide coacervate microdroplets. ${ }^{[201]}$ Images of patterned 
dipeptide supramolecular hydrogels generated using (ii) 1D and (ii) 2D ultrasound standing waves. Scale bars: main $=5 \mathrm{~mm}$ and inset $=1 \mathrm{~mm}$. Reproduced under the terms of the Creative Commons CC-BY-NC license. ${ }^{[201]}$ Copyright 2018, The Authors, published by Wiley-VCH Verlag GmbH \& Co. KGaA. (C) (i) Schematic of work by Liu et al. describing light-mediated stiffness patterning within protein/PEG-based hydrogels. ${ }^{[209]}$ (ii) The obtained hydrogels possess a stiffness-dependent color profile, with stiffer regions colored in yellow under ambient light and softer regions appearing clearer. (iii) Exposure to light $(\lambda=470 \mathrm{~nm})$ across the entire hydrogel (cycle 1) or over selected areas via a photomask (cycles 2 and 3) resulted in temporary softening followed by complete recovery. Hydrogel diameter $\approx 1 \mathrm{~cm}$ and thickness $\approx 200 \mu \mathrm{m}$. Reproduced with permission. Copyright 2018, Wiley-VCH Verlag GmbH \& Co. KGaA. 
A
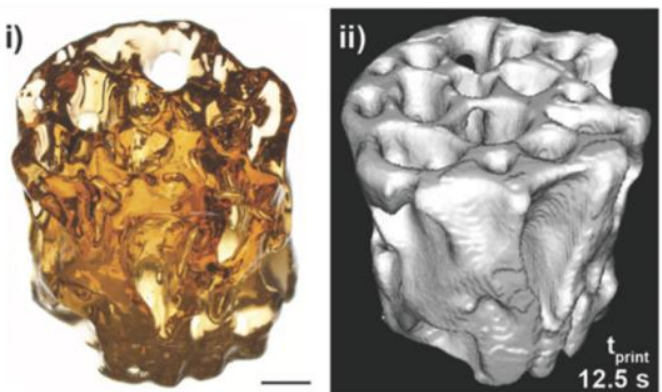

B

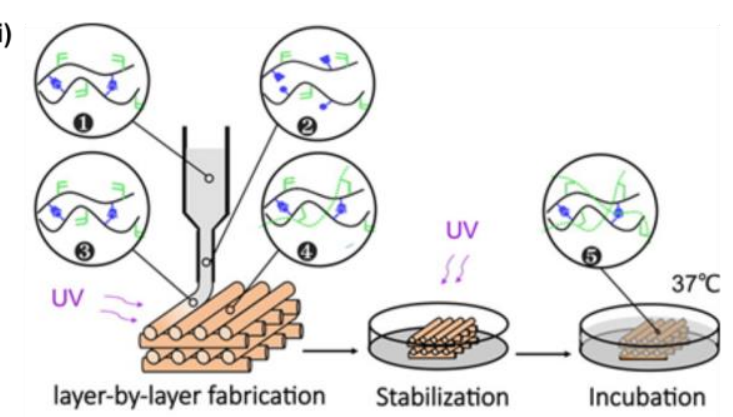

ii)

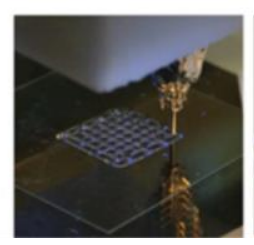

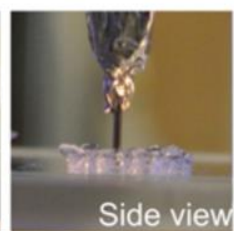

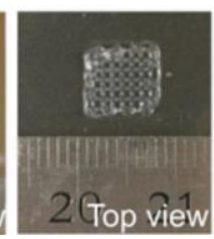

C

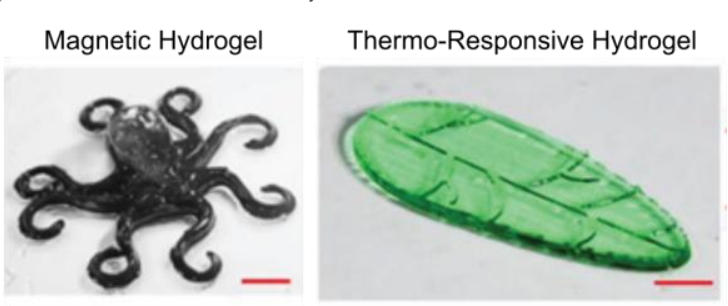

D

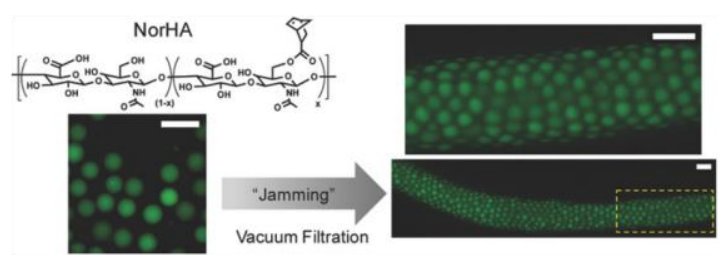

竞
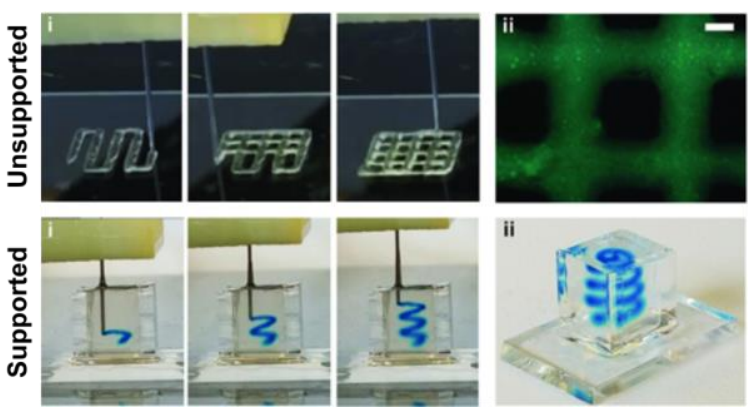

Figure 5. Hydrogel-based biofabrication. (A) (i) Volumetric bioprinting, recently developed by Bernal et al., allowed the rapid fabrication of complex 3D hydrogel constructs using light projection photocrosslinking of GelMA. (ii) This was used for trabecular bone engineering, as observed using micro computed tomography imaging. ${ }^{[226]}$ Scale bars: $2 \mathrm{~mm}$. Reproduced under the terms of the Creative Commons CC-BY-NC license. ${ }^{[226]}$ Copyright 2019, The Authors, published by Wiley-VCH Verlag GmbH \& Co. KGaA. (B) (i) Schematic of the hydrogel fabrication process used by Ouyang et al., in which a shear-thinning hydrogel is extruded as a liquid and gels via host-guest interactions. ${ }^{[229]}$ UV light is then used to mediate crosslinking between methacrylate moieties on the HA backbone. (ii) Representative images of the 3D printed structures. Adapted with permission. Copyright 2016, American Chemical Society. (C) Representative images of 3D printed structures obtained by using Carbomer-based inks developed by Chen et al. ${ }^{[230]}$ (i) An ink incorporating ferromagnetic nanoparticles was used to 
print magnetic hydrogels, while a PNIPAM-based ink was used to print thermo-responsive hydrogel constructs (ii). Scale bars: $1 \mathrm{~mm}$. Adapted with permission. Copyright 2019, WileyVCH Verlag GmbH \& Co. KGaA. (D) Work by Highley et al., in which 2 wt\% norbornenefunctionalized HA (NorHA) microgels (green) are packed via vacuum filtration into a solid filament. ${ }^{[233]}$ Scale bars: $200 \mu \mathrm{m}$. The microgel-based ink was then used to 3D print structures onto a glass plate (unsupported) or within self-healing hydrogels (supported). Scale bars: 500 $\mu \mathrm{m}$. Reproduced under the terms of the Creative Commons CC-BY-NC license. ${ }^{[233]}$ Copyright 2019, The Authors, published by Wiley-VCH Verlag GmbH \& Co. KGaA. 
A

B
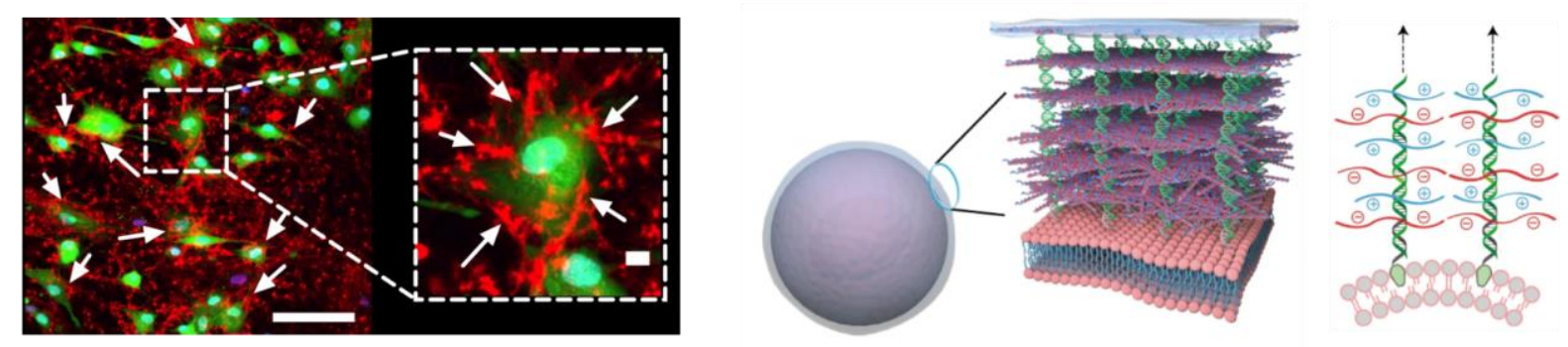

C

i)

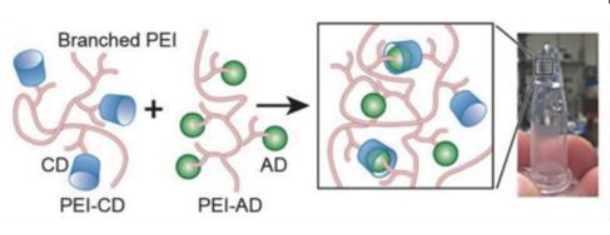

ii) Minicircle DNA Cas9 protein
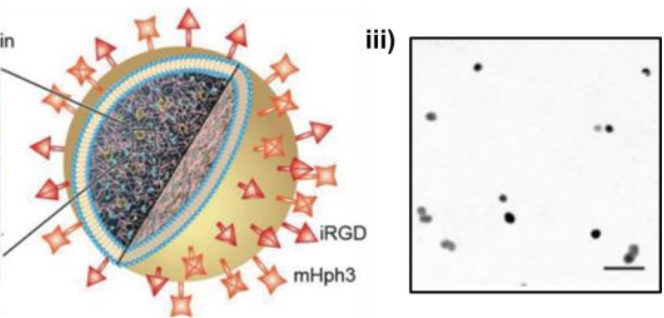

Figure 6. Pericellular gelation and nanoparticle-templated nanogel fabrication. (A) Livecell confocal fluorescence microscopy from Deller et al. showing the formation of fluorescently-labeled fibrin fibers (red) around the surface of thrombin-coated human mesenchymal stem cells (green). Scale bars: main $=100 \mu \mathrm{m}$ and inset $=10 \mu \mathrm{m} \cdot{ }^{[241]}$ Reproduced under the terms of the Creative Commons CC-BY-NC license. ${ }^{[241]}$ Copyright 2019, The Authors, published by Springer Nature Limited. (B) Schematic of the strategy taken by Shi et $a l$. to form an alginate-DNA polymer network hydrogel that could be further crosslinked with polylysine around the surface of a cell. Reproduced under the terms of the Creative Commons CC-BY-NC license. ${ }^{[244]}$ Copyright 2019, The Authors, published by Springer Nature Limited. (C) (i) Schematic of the approach taken by Chen et al. using host-guest complexation between cyclodextrin and adamantane groups to form a self-assembled hydrogel. (ii) Schematic of liposome-templated host-guest nanogels encapsulating minicircle DNA and Cas9 protein, (iii) which were imaged via transmission electron microscopy. Scale bar: $500 \mathrm{~nm}$. Adapted with permission. ${ }^{[252]}$ Copyright 2017, Wiley-VCH Verlag GmbH \& Co. KGaA. 
Table 1. Interactions leading to hydrogelation and selected literature examples.

\begin{tabular}{|c|c|}
\hline \multicolumn{2}{|l|}{ Covalent Bonding } \\
\hline Reactions between polymer chains & 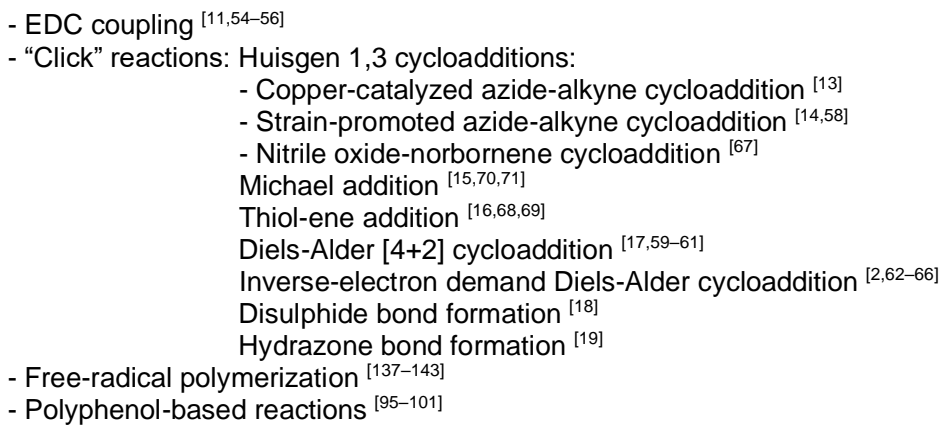 \\
\hline $\begin{array}{l}\text { Reactions between polymer chains and } \\
\text { nanoparticles }\end{array}$ & $\begin{array}{l}\text { - Thiol-ene addition }{ }^{[20,21]} \\
\text { - Free-radical polymerization }{ }^{[22]} \\
\text { - EDC coupling }{ }^{[23]} \\
\text { - Coordinate covalent bond formation }{ }^{[84]}\end{array}$ \\
\hline \multicolumn{2}{|l|}{ Electrostatic Interactions } \\
\hline \multicolumn{2}{|l|}{ Ion-polymer interactions ${ }^{[24-29]}$} \\
\hline \multicolumn{2}{|l|}{ Polymer-polymer interactions ${ }^{[31,32]}$} \\
\hline \multicolumn{2}{|l|}{ Other Noncovalent Interactions } \\
\hline \multicolumn{2}{|l|}{ Polymer-polymer interactions ${ }^{[33,35,36,72-76]}$} \\
\hline
\end{tabular}


Table 2. Intrinsic hydrogelation triggers and selected literature examples.

\begin{tabular}{|c|c|}
\hline \multicolumn{2}{|l|}{ Temperature Changes } \\
\hline Cooling & $\begin{array}{l}\text { - Gelatin hydrogels }{ }^{[41]} \\
\text { - Agarose hydrogels }{ }^{[42]} \\
\text { - Low-molecular-weight gelators }{ }^{[43]}\end{array}$ \\
\hline Heating & - Thermo-responsive amphiphilic block copolymer hydrogels ${ }^{[44,47-52]}$ \\
\hline \multicolumn{2}{|l|}{ Component Mixing } \\
\hline $\begin{array}{l}\text { Noncovalent interactions between } \\
\text { complementary groups }\end{array}$ & $\begin{array}{l}\text { - Mixing-induced two-component hydrogels }(\mathrm{MITCH})^{[53]} \\
\text { - DNA-PNA methacrylamide hydrogels }{ }^{[72]} \\
\text { - DNA-polypeptide hydrogels } \\
\text { - Enantiomer-functionalized dextran hydrogels }{ }^{[74]} \\
\text { - Host-guest cyclodextrin hydrogels }{ }^{[76]} \\
\text { - Cucurbit[n]uril hydrogels }{ }^{[7]]}\end{array}$ \\
\hline Covalent crosslinking & $\begin{array}{l}\text { - Gelatin-based hydrogels }{ }^{[11,55,63]} \\
\text { - Collagen-based hydrogels }{ }^{[54]} \\
\text { - Fibrinogen-based hydrogels }{ }^{[56]} \\
\text { - Chitosan-based hydrogels } \\
\text { - Alginate-based hydrogels }{ }^{[64]} \\
\text { - HA-based hydrogels }{ }^{[65,66]} \\
\text { - PEG-based hydrogels }{ }^{[58,60-62,66,67,69-71]}\end{array}$ \\
\hline Nanoparticle-based & $\begin{array}{l}\text { - Methylcellulose-based hydrogels }{ }^{[78,79]} \\
\text { - HA-based hydrogels }{ }^{[79,82]} \\
\text { - PEG-based hydrogels }{ }^{[80,81,84]} \\
\text { - DNA-based hydrogels }{ }^{[83]}\end{array}$ \\
\hline \multicolumn{2}{|l|}{ Change in $\mathrm{pH}$} \\
\hline Charge screening & $\begin{array}{l}\text { - Collagen }{ }^{[85-87]} \\
\text { - (PAGE-PEO-PAGE)-based hydrogels }{ }^{[88]} \\
\text { - Zwitterionic polyethyleneimine }{ }^{[89]}\end{array}$ \\
\hline Covalent crosslinking & - PEG-based hydrogels ${ }^{[90]}$ \\
\hline Catalytic gelation & - Trishydrazone amphiphile-based hydrogels ${ }^{[91]}$ \\
\hline \multicolumn{2}{|c|}{ Change in Oxidation State via the Addition of Oxidizing Species } \\
\hline Catechol-functionalized & $\begin{array}{l}\text { - Poly (p-phenylene oxide)/PEG-based hydrogels }{ }^{[96]} \\
\text { - Gelatin-based hydrogels }{ }^{[97]} \\
\text { - Mussel adhesive protein hydrogels }{ }^{[98]}\end{array}$ \\
\hline Pyrogallol-functionalized & $\begin{array}{l}\text { - Gelatin-based hydrogels }{ }^{[100]} \\
\text { - HA-based hydrogels }{ }^{[101]}\end{array}$ \\
\hline \multicolumn{2}{|l|}{ Enzyme Addition } \\
\hline Transglutaminase catalysis & $\begin{array}{l}\text { - Fibrinogen }{ }^{[102]} \\
\text { - Fibrin hydrogels }{ }^{[102]}\end{array}$ \\
\hline Glucose oxidase catalysis & $\begin{array}{l}\text { - Heparin-based hydrogels }{ }^{[103]} \\
\text { - PEG-based hydrogels }{ }^{[103]}\end{array}$ \\
\hline Lysyl oxidase catalysis & - Peptide-based hydrogels ${ }^{[105]}$ \\
\hline Hydrogen peroxidase catalysis & $\begin{array}{l}\text { - HA-based hydrogels }{ }^{[106]} \\
\text { - Glycopolypeptide-based hydrogels }{ }^{[107]} \\
\text { - PEG-based hydrogels }{ }^{[108,110]} \\
\text { - Gelatin-based hydrogels }{ }^{[109,110]}\end{array}$ \\
\hline \multicolumn{2}{|l|}{ Electromagnetic Radiation } \\
\hline Uncaging of reactive groups & - PEG-based hydrogels ${ }^{[115]}$ \\
\hline
\end{tabular}


Table 3. Indirect hydrogelation triggers and selected literature examples.

\begin{tabular}{|c|c|}
\hline \multicolumn{2}{|l|}{ Temperature } \\
\hline $\begin{array}{l}\text { Release of crosslinking species from } \\
\text { a temperature-responsive carrier }\end{array}$ & $\begin{array}{l}\text { - Alginate hydrogels }{ }^{[120]} \\
\text { - Fibrinogen hydrogels }{ }^{[120]} \\
\text { - PEG-based hydrogels }\end{array}$ \\
\hline \multicolumn{2}{|l|}{ Ultrasound } \\
\hline $\begin{array}{l}\text { Release of crosslinking species from } \\
\text { an ultrasound-responsive carrier }\end{array}$ & - Fibrinogen hydrogels ${ }^{[123]}$ \\
\hline \multicolumn{2}{|l|}{ Electromagnetic Radiation } \\
\hline Irradiation with ultraviolet light & $\begin{array}{l}\text { - PEG-based hydrogels }{ }^{[137,145,146]} \\
\text { - HA-based hydrogels }{ }^{[139,148]} \\
\text { - Gelatin-based hydrogels }{ }^{[138,147]} \\
\text { - Collagen-based hydrogels } \\
\text { - Alginate-based hydrogels }{ }^{[141]} \\
\text { - Chitosan-based hydrogels }{ }^{[142]}\end{array}$ \\
\hline Irradiation with red light & $\begin{array}{l}\text { - Acrylamide-based hydrogels }{ }^{[150]} \\
\text { - PEG-based hydrogels }{ }^{1150,151]}\end{array}$ \\
\hline Upconversion nanoparticles (NIR) & - Pluronic ${ }^{\circledR} /$ PEG hydrogels ${ }^{[152]}$ \\
\hline Plasmonic nanostructures (NIR) & $\begin{array}{l}\text { - HA-based hydrogels }{ }^{[113]} \\
\text { - PEG-based hydrogels }{ }^{[114]} \\
\text { - Alginate-based hydrogels }{ }^{[156]}\end{array}$ \\
\hline $\begin{array}{l}\text { Release of crosslinking species from } \\
\text { light-responsive carrier (NIR) }\end{array}$ & - Fibrinogen hydroge ${ }^{[158]}$ \\
\hline
\end{tabular}




\section{Biographies}

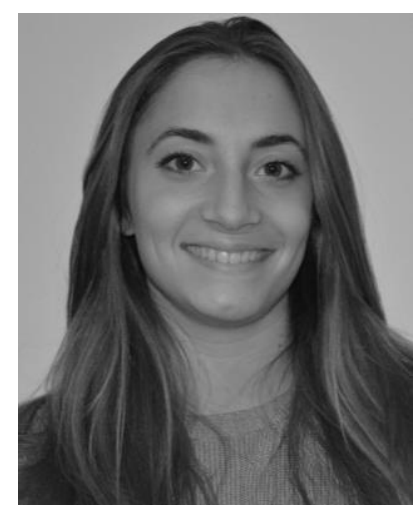

Valeria Nele recently received her Ph.D. from Imperial College London under the supervision of Professor Molly Stevens after completing an MSc in Chemical Engineering at the University of Naples Federico II. Her research focuses on the development of stimuli-responsive nanoparticles and biomaterials for biomedical applications.

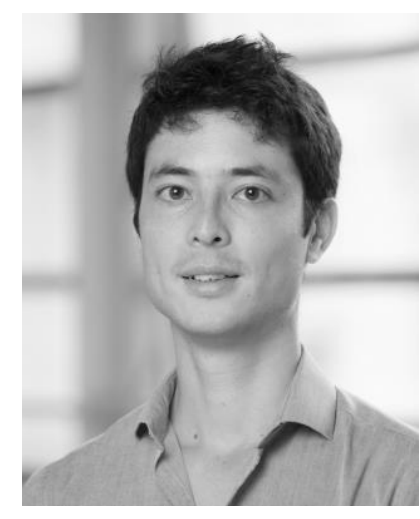

James Armstrong received his Ph.D. from the School of Chemistry at the University of Bristol in 2015, and is currently an MRC/UKRI Research Fellow in the Department of Materials at Imperial College London. His research focus is on the development of novel strategies for complex tissue engineering, including new acoustic cell patterning methods for musculoskeletal tissue engineering. 


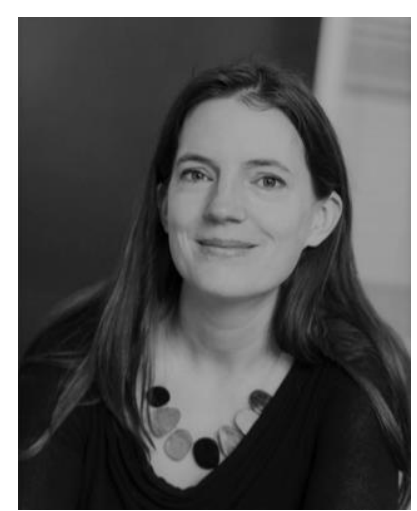

Molly Stevens is a Professor of Biomedical Materials and Regenerative Medicine at Imperial College London and the Director of the UK Regenerative Medicine Programme Hub for Smart Materials. She is Foreign Member of the National Academy of Engineering and a Fellow of seven UK academies, including the Royal Society of Chemistry where she is president of the Division of Materials Chemistry. Her research focuses on material-based approaches for applications in regenerative medicine and biosensing. 


\section{Table of Contents}

This Progress Report provides a critical overview of recent advances in hydrogel design, with a focus on the currently available approaches to trigger hydrogelation (e.g., temperature, $\mathrm{pH}$, enzymes, light, ultrasound). These triggers are presented within a new classification system and illustrated with key examples and applications in biomedical science. Future opportunities are outlined with the aim of aiding trigger selection and inspiring the next generation of gelation mechanisms.

Keyword: hydrogels

Valeria Nele, Jonathan P. Wojciechowski, James P. K. Armstrong* \& Molly M. Stevens*

\section{Tailoring gelation mechanisms for advanced hydrogel applications}

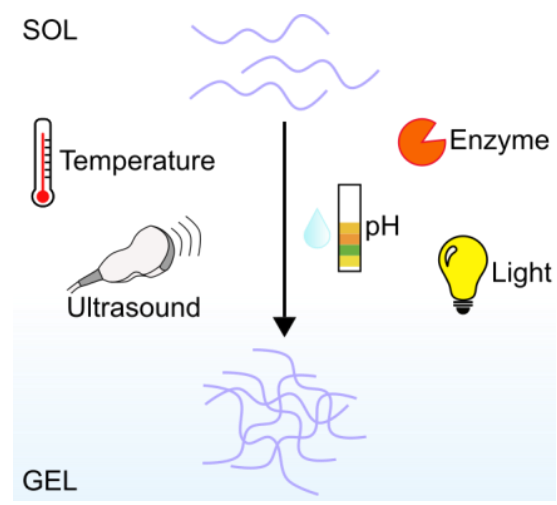

TOC figure 